\title{
Caracterización de materiales y análisis técnico de tejidos medievales
}

\author{
Pilar Borrego, Estrella Sanz, Pedro Pablo Pérez, Ana Albar, Cristina Partearroyo, Ángela Arteaga, \\ Susanna Marras, Ana Roquero
}

Resumen Dentro del Plan Nacional de Investigación en Conservación coordinado por el Instituto de Patrimonio Cultural de España (IPCE) y en colaboración con el Instituto Valencia de Don Juan de Madrid, se ha desarrollado un proyecto interdisciplinar aplicado a un conjunto de tejidos medievales, basado en técnicas de análisis que permiten un conocimiento más preciso de la tecnología textil y caracterización de los materiales constituyentes.

Los análisis efectuados en este corpus nos han permitido establecer diferentes centros de producción, elaborar una relación detallada de las técnicas textiles empleadas en los diferentes periodos, así como identificar variaciones en la composición de los hilos metálicos y colorantes, en función de la zona geográfica en la que han sido producidos.

Palabras clave: tejidos, técnicas textiles, tintes, hilos metálicos

\section{Characterization of materials and technical analysis of medieval fabrics}

Abstract: An interdisciplinary project has been carried out in the framework of the National Research Plan in Cultural Heritage (Plan Nacional de Investigación en Conservación, PNIC) and in collaboration with the Valencia de Don Juan Institute of Madrid. The project is focused on the study of a set of medieval fabrics using analysis techniques. This study leads to a more precise knowledge of the textile technology and the characterization of the used materials.

The analysis let us know different production centers, with a detailed relation of manufacturing textile techniques for different periods, and identify variations in the composition of metal threads depending on the geographical region where they have been produced.

Keyword: textiles, textile techniques, dyes, metal threads

\section{Caraterização de materiais e análises técnicas de tecidos medievales}

Resumo: No âmbito do Plano Nacional de Investigação em Conservação, coordenado pelo Instituto de Património Cultural de Espana (IPCE) e em colaboração com o Instituto Valencia de Don Juan de Madrid, desenvolveu-se um projeto interdisciplinar aplicado a um conjunto de tecidos medievais, baseado em técnicas de análise que permitem um conhecimento mais preciso sobre a tecnologia têxtil e para a caracterização dos materiais constituintes.

As análises efetuadas neste corpus permitiu-nos estabelecer diferentes centros de produção, elaborar uma relação detalhada das técnicas têxteis empregues nos diferentes períodos, assim como identificar variações na composição dos fios metálicos e corantes em função da zona geográfica em que foram produzidos.

Palavras-chave: tecidos, técnicas têxteis, tintas, fios metálicos 


\section{Introducción}

En este artículo se muestra los resultados del estudio interdisciplinar aplicado a un corpus de más de sesenta tejidos, pertenecientes a diversas colecciones ${ }^{1}$ y datados entre los siglos $\mathrm{X}$ y $\mathrm{XVI}^{2}$.

En este estudio se ha abordado el análisis de las materias primas, técnicas de fabricación, fuentes iconográficas y estado de conservación, con la finalidad de obtener una mejor comprensión de las trasferencias técnicas y posible ubicación de los centros de producción.

El estudio efectuado no se ha reducido únicamente a una descripción o comparación iconográfica con otros ejemplares similares, sino que se ha ampliado con la caracterización de los diferentes materiales presentes, mediante técnicas analíticas que nos permiten identificar los compuestos empleados en su manufactura y profundizar en las diferentes técnicas textiles desarrolladas.

\section{Análisis técnico}

El arte textil en al-Andalus experimentó un gran desarrollo con una evolución desde técnicas simples como el tafetán (con decoración en técnica de tapicería, tafetán liseré o tafetán con efecto de perdido por trama), a ligamentos de gran complejidad como el taqueté, el samito y el lampás.

Una gran variedad de técnicas textiles han sido identificadas en el conjunto estudiado. El ligamento más frecuente es el tafetán de forma individual, como base de un bordado o combinado con otros ligamentos como el lampás o el tafetán doble en las franjas de tapicería.

En determinadas zonas del tejido de un pequeño fragmento con técnica derivada del tafetán (ASECT 7.3i), localizado en el interior de una de las bolsas relicario del arca de San Eugenio, la trama que efectúa el fondo ejecuta también la decoración, y se eleva por encima de dos o más urdimbres en función del motivo decorativo programado (tafetán liseré).[figura 1]

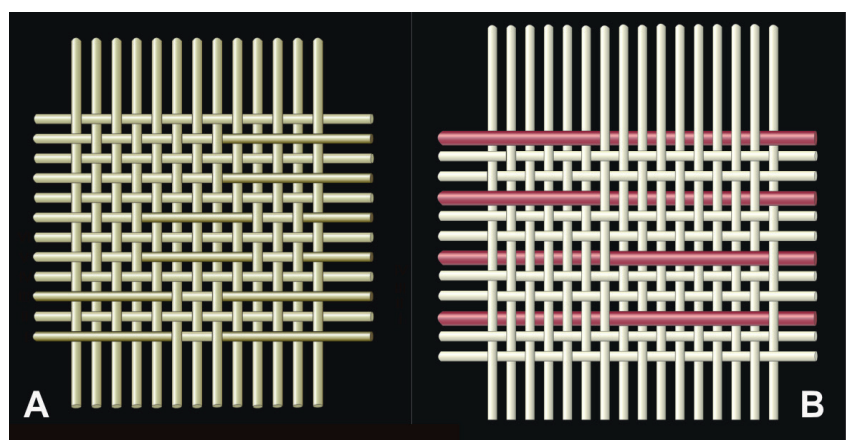

Figura 1.- Representación del ligamento tafetán liseré (A) y tafetán con efecto de perdido (B).
Otra variedad de este ligamento está representada en dos velos femeninos (IVDJ 2075; IVDJ 2076), con fondo en tafetán de seda muy ligero, y en el motivo decorativo una trama suplementaria dibuja el diseño al pasar por encima de un número determinado de urdimbres (tafetán con efecto de perdido por trama). En este caso, el diseño se produce con una trama auxiliar, mientras que en el tafetán liseré la misma trama tiene dos funciones, fondo y decoración. [figura 1]

El fragmento de tejido IVDJ 2061, procedente del sepulcro del Infante Don Felipe, que posiblemente forrase el ataúd, presenta una decoración de bandas horizontales con una alternancia tanto en el color de la trama como en el tipo de ligamento, que origina franjas en tafetán, tafetán liseré y doble cara trama (bayadera)( De Jongue \& Verhecken Lammens: 122-124).

En el tejido nazarí IVDJ 2207, con base de tafetán de lino, el diseño se dibuja con un cordoncillo que se rellena con un bordado en punto de espiga, mediante sedas policromas de vivos colores. El motivo decorativo del bordado, con leones afrontados separados por el árbol de la vida y un escudo invertido, está representado en los fragmentos elaborados en telar IVDJ 2114 y HSA 985. Este motivo fue muy popular en el s. XV-XVI en la elaboración de tejidos, así como en bordados y alfombras ${ }^{3}$.

El ligamento de sarga se muestra en el fragmento del galón de la casulla de San Valero (IVDJ 8360) y en la bolsa relicario roja del arca de San Eugenio (ASECT 7.3) [figura 2]. Esta bolsa alberga en su interior un fragmento de almaizar amarillo (ASECT 7.3a), que sirve de envoltorio de pequeños tejidos con diferentes técnicas textiles, como si de un muestrario de la época se tratase. Dos de estos tejidos, en forma de hatillo, llevan cosidos unas cartelas alusivas a San Dionisio y San Eugenio.
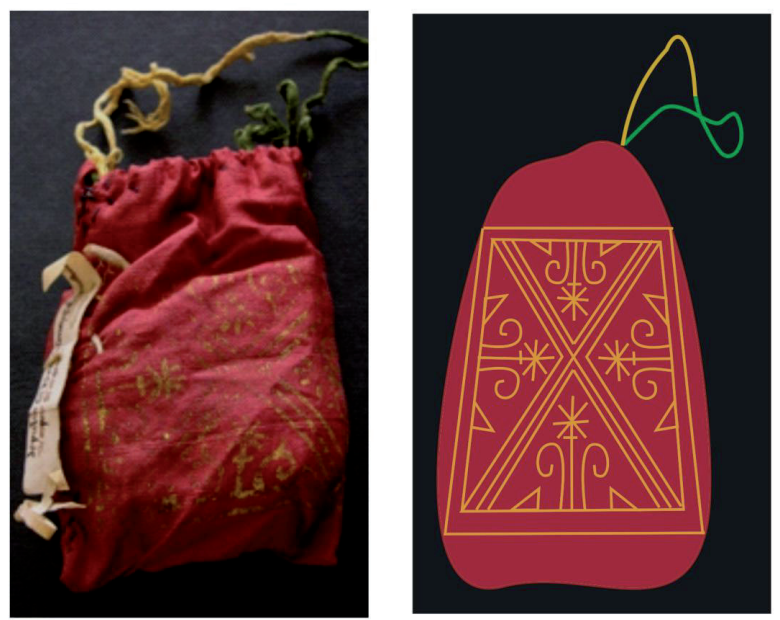

Figura 2.- Bolsa relicario del interior del arca de San Eugenio

El fragmento del galón de la casulla de San Valero (IVJ 8360) está tejido técnica de sarga de urdimbres múltiples, conocido como banda de Palermo (Vial \& Fayard 1995: 237-241), donde hilos de urdimbre de 
diferente color se combinan, bien con una trama de fondo marrón o con una suplementaria metálica, dando lugar a sargas con una estructura diferente en cuanto al curso, efecto y dirección, lo que origina una alternancia de sargas en sentido urdimbre y trama en función del hilo que participa.

El samito está representado en este corpus en dos modalidades diferentes, si atendemos a la composición de las fibras e hilos metálicos.

Los elaborados en al-Ándalus se caracterizan por una uniformidad en su composición, seda en la urdimbre y trama y un sustrato orgánico de piel dorada en el hilo entorchado, composición que a partir de fines del XIII aumentará su contenido en plata hasta desaparecer en algunos tejidos en el siglo XV y ser sustituido por seda de color amarillo. Así, los tejidos resultaban más baratos para exportarlos desde el reino nazarí de Granada (1238-1492) (Partearroyo: 1992, p. 335).

En los samitos mudéjares del siglo XIII, la urdimbre de base es sustituida por lino, al igual que el hilo de alma del entorchado. Otra diferencia con respecto a los samitos de al-Andalus es el tipo de hilo entorchado, identificando en estos ejemplares plata dorada sobre un sustrato de intestino animal.

Una excepción dentro de estos tejidos elaborados en territorio cristiano se ha detectado en el pellote de Fernando de la Cerda, donde la urdimbre de base y el alma del entorchado se han perdido casi por completo. En el análisis morfológico se ha identificado ramio en la urdimbre y mezcla de ramio y lino en el alma del entorchado.

Es el lampás la técnica más empleada en el periodo nazarí y tiene su origen en Almería en el periodo almorávide (1086-1147), con una ejecución especial que va a ser exclusiva de la península Ibérica (Shepherd 1957: 377-378).

La estructura de esta modalidad de lampás almorávide emplea una urdimbre de ligadura cada cuatro urdimbres de fondo (simples o dobles), a excepción del fragmento del arca de San Eugenio donde la proporción es de una urdimbre de ligadura cada seis de fondo simples. La disposición de estas urdimbres puede ser de forma irregular en el tejido ASECT 7.2 [figura 3]; en tafetán mixto 1-1-2, donde las urdimbres pueden ser dobles o simples; o bien en tafetán con hilos simples o dobles (tejido de los leones de Cuenca). Esta última estructura persiste en el periodo almohade (11471213) en la banda decorativa del alba de Ximénez de Rada (1247), con una gama cromática idéntica al tejido de los leones de la Catedral de Cuenca, pero con un diseño más geométrico dispuesto en franjas horizontales, al gusto de los nuevos gobernantes (Borrego 2005: 96).

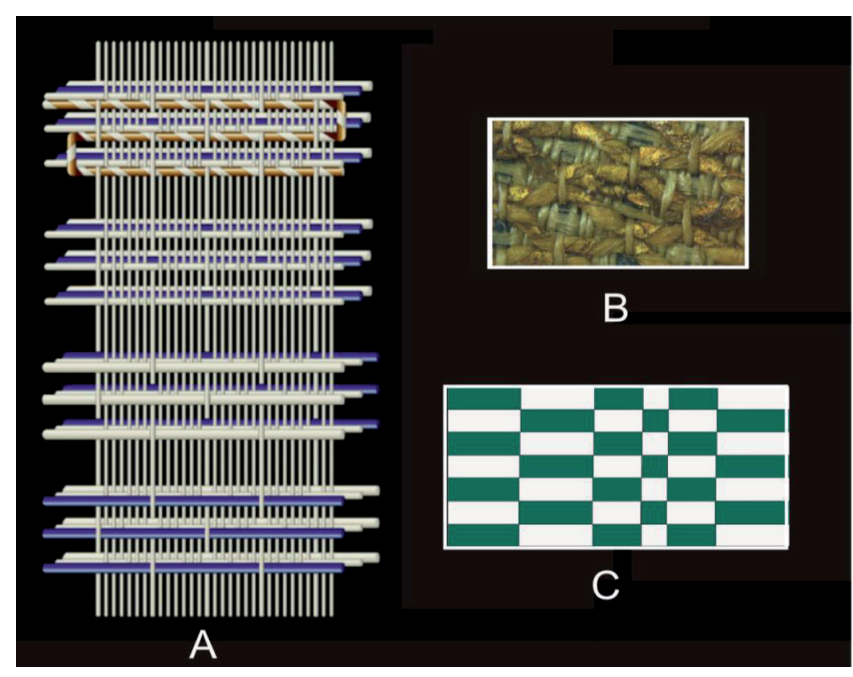

Figura 3.- Representación tridimensional del lampás del fragmento ASECT 7.2 (A). Detalle del efecto de nido de abeja originado con el hilo metálico (B). Representación en cuadrícula del tafetán irregular (C).

La urdimbre de ligadura en el lampás andalusí trabaja con la trama decorativa en tafetán, pero es la de fondo la que modifica la estructura con el paso del tiempo, innovando con diferentes recursos que producen efectos de mayor relieve al aplicar, en el fondo del tejido, la sarga y el raso como en los tejidos del periodo granadino nazarí de los siglos XIV y XV.

\section{Análisis de los colorantes}

La caracterización de los colorantes se ha efectuado mediante cromatografía líquida acoplada a un detector diodo array y un espectrómetro de masas con analizadores de cuadrupolo y tiempo de vuelo (HPLC-DAD-QTOFMS), que permite la separación e identificación de los componentes en mezclas complejas. Cada patrón viene determinado por un tiempo de retención cromatográfico, espectro de ultravioleta-visible (UV-vis), facilitado por el diodo array, así como su masa exacta y su espectro de masas-masas (MS/MS), detectados por el QTOF. Esta información permite la comparación automática de los resultados obtenidos al analizar las muestras con la base de datos creada tras el análisis de los patrones.

El único tinte azul empleado en este corpus ha sido el índigo, procedente de alguna especie de Indigofera o de la Isatis tinctoria L, fuente del tinte conocida como hierba pastel o glasto. En el caso de las muestras azules de dos tejidos del arca de San Eugenio (ASECT 6.1c y ASECT 7.2) el índigo se ha combinado con madera de palo brasil. En el hilo azul de trama del tejido IVDJ 2084 el índigo se mezcla con un liquen del grupo de las denominadas orchillas y en IVDJ 2085 se encuentra el mismo resultado, con la adición de granza. La presencia de índigo con madera de palo brasil $\mathrm{u}$ orchilla, dos tintes que se degradan con mucha facilidad, nos podría sugerir una tonalidad púrpura en origen. 
La identificación del liquen de orchilla se ha realizado en base a la detección de sus principales componentes, la a-amino orceína y la a-hidroxi orceína. En el fragmento ASECT 7.3b la combinación con índigo se ha verificado tanto en trama como urdimbre pero en diferente proporción, lo que produce una tonalidad distinta en función del componente mayoritario, dando como resultado visual de esta mezcla un tejido tornasolado.

En una variedad de tejidos han sido detectados como únicos responsables del color rojo el quermes, la granza, la madera de palo brasil, la cochinilla, la laca y el cártamo. Estos tintes en otras piezas se presentan también combinados con uno o más colorantes en distinta proporción en función de la gama que se ha querido obtener, o bien para abaratar el producto en hilos que, por el ligamento elegido, son menos visibles en el anverso del tejido.

Dentro de los colorantes rojos, el grupo de las antraquinonas incluye, por un lado, aquellos que se obtienen de las raíces de diferentes especies de plantas de la familia Rubiaceae y por otro, los que proceden de las hembras de una serie de insectos de la superfamilia Coccoidea.

Los tintes obtenidos de la familia Rubiaceae se conocen de modo genérico como granzas. Los componentes responsables del color en estos tintes pueden ser: alizarina, purpurina, xantopurpurina, pseudopurpurina, rubiadina, munjistina y morindona, entre otras muchas antraquinonas. En función de la composición de las antraquinonas presentes se puede determinar la especie originaria del tinte.

Los diferentes tipos de Granza identificados en este corpus han sido la Rubia ticntorum L., posiblemente la Rubia peregrina L. y una tercera especie cuyo componente principal es la rubiadina, donde no se detecta alizarina y la purpurina se encuentra en muy baja proporción.

Los compuestos responsables del color en los tintes obtenidos de los insectos de la superfamilia Coccoidea son principalmente ácido carmínico, ácido quermésico, ácido flavoquermésico y ácidos lacaicos, todos ellos también con estructura base de antraquinona.

De todos los insectos que producen estos tintes se encuentran: la cochinilla polaca (Porphyrophora polonica L.), la cochinilla armenia (Porphyrophora hamelii Brandt), la cochinilla americana (Dactylopius coccus Costa), el quermes (Kermes vermilio Planchon) y el tinte laca o laca india (Kerria lacca Kerr) ( Hofenk de Graaff et al. 2004).

Respecto a las cochinillas, el componente mayoritario en los tres casos es el ácido carmínico; pero mientras la cochinilla polaca contiene una proporción de ácido quermésico muy superior (puede llegar al 40\%), lo que hace posible su diferenciación del resto, la cochinilla armenia y la americana presentan una composición muy similar (inferior al 4\%), por lo que su distinción puede resultar muy complicada
(Wouters \& Verhecken 1989). El tinte laca se caracteriza por contener diferentes tipos de ácidos lacáicos y el quermes está compuesto principalmente de ácido quermésico y, en menor proporción, de ácido flavoquermésico (Wouters \& Verhecken 1989).

La madera de palo brasil ha sido identificado por la presencia de brasileína (producto de oxidación de la brasilina, principal componente de la madera del palo brasil que se degrada por envejecimiento) y un compuesto denominado en la bibliografía como "Type C", todavía sin identificar, y que se utiliza como marcador de las especies de Caesalpinia, una de las posibles fuentes de este tinte rojo (Mantzouris et al. 2011).

En el cártamo o alazor (Carthamus tinctorius L.), el principal componente es la cartamina, responsable de las tonalidades rosas que produce. Junto con la cartamina, el alazor contiene compuestos amarillos que suelen ser deliberadamente eliminados antes del teñido. Aunque este tinte ha sido detectado en casos excepcionales, las fuentes documentales lo mencionan como una de las plantas más utilizadas en al-Andalus, señalando que se podía utilizar como tinte amarillo o rojo en función de cómo fuese procesado (Meyer 2000). Este tinte ha sido localizado en el tejido IVDJ 2082, tanto en la trama decorativa como en el alma del hilo entorchado, así como en el fragmento MTIB 101158. En esta última muestra el cártamo ha sido identificado por la fluorescencia anaranjada inducida por la radiación ultravioleta [figura 4].

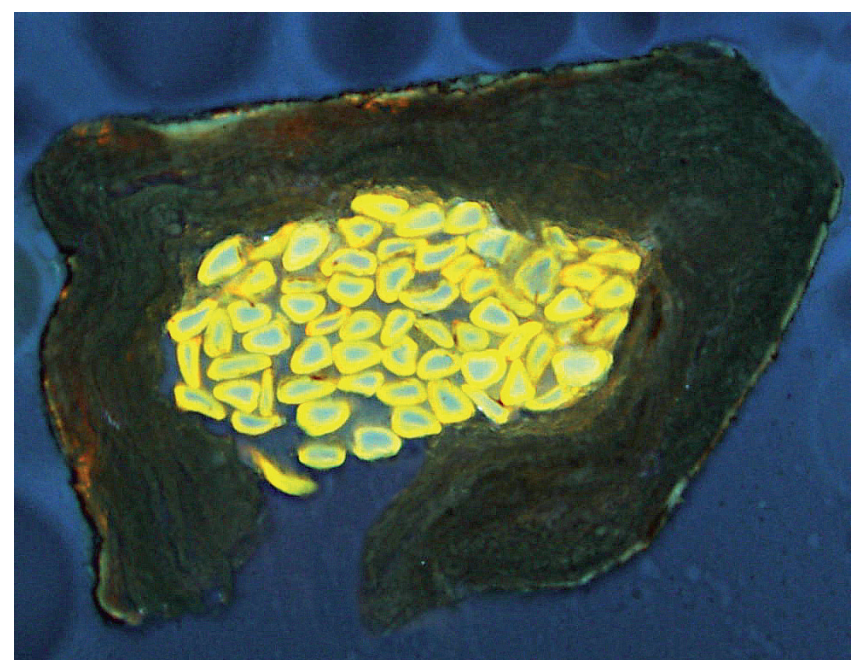

Figura 4.- Sección transversal del hilo entorchado con alma de seda teñida con cártamo.

Llama la atención el resultado obtenido en los tejidos del interior de la bolsa relicario roja estampada en oro (ASECT 7.3) [figura 2]. Por un lado tinte laca en el fragmento ASECT 7.3d y cochinilla, en el hilo de costura del fragmento ASECT7.3b, dos tintes rojos que no habían sido detectados anteriormente en ningún tejido hasta ahora analizado en el IPCE y de inequívoca procedencia Andalusí4. 
Sabemos de la existencia de otra bolsa roja estampada en oro, procedente del Museo Diocesano de Liège, cuyo diseño, de un león rampante enmarcado entre dos líneas doradas, es comparado con las placas de un incensario conservado en el tesoro de San Marcos de Venecia, producido en el s. XIl en Bizancio o en el sur de Italia al estilo bizantino (Pirenne 2005: 136). La forma rectangular de esta bolsa, las medidas y el cierre con el cordón de seda tiene un gran parecido con la de San Eugenio, aunque el diseñoestampadoen oroen estaúltima es geométrico, semejante al motivo representado en el manuscrito de la Ascensión de Cristo de las homilías de Jacobo Kokkinobaphos, producido en Constantinopla en el s. XII y conservado en la biblioteca Nacional de Paris https://es.pinterest.com/pin/346355027572398877 [consulta 10/07/2017].

La mezcla de colorantes procedentes de quermes y cochinilla también ha sido detectada en la trama del forro con motivos de dragones y en la de pájaros del manto de Roger II de Sicilia, en la urdimbre y trama de un par de medias del s.XII y en la trama de la banda de unos zapatos del s. XII-XIII, todos ellos atribuidos a los talleres reales de Palermo (De Graaff 2006: 128-131).

De Graaff señala también la presencia de cochinilla en un tejido bizantino custodiado en la Catedral de Bressanone, Italia. En este caso la trama roja está compuesta por la mezcla de cochinilla y granza.

En uno de los pequeños fragmentos del interior de la bolsa relicario roja, tejido en técnica de samito (ASECT 7.3c) [figura 5], la decoración con líneas en zig-zag recuerdan las sedas figuradas bizantinas con representación de animales fantásticos del s. X-XI. En este tejido, el tinte rojo empleado en la trama es laca.

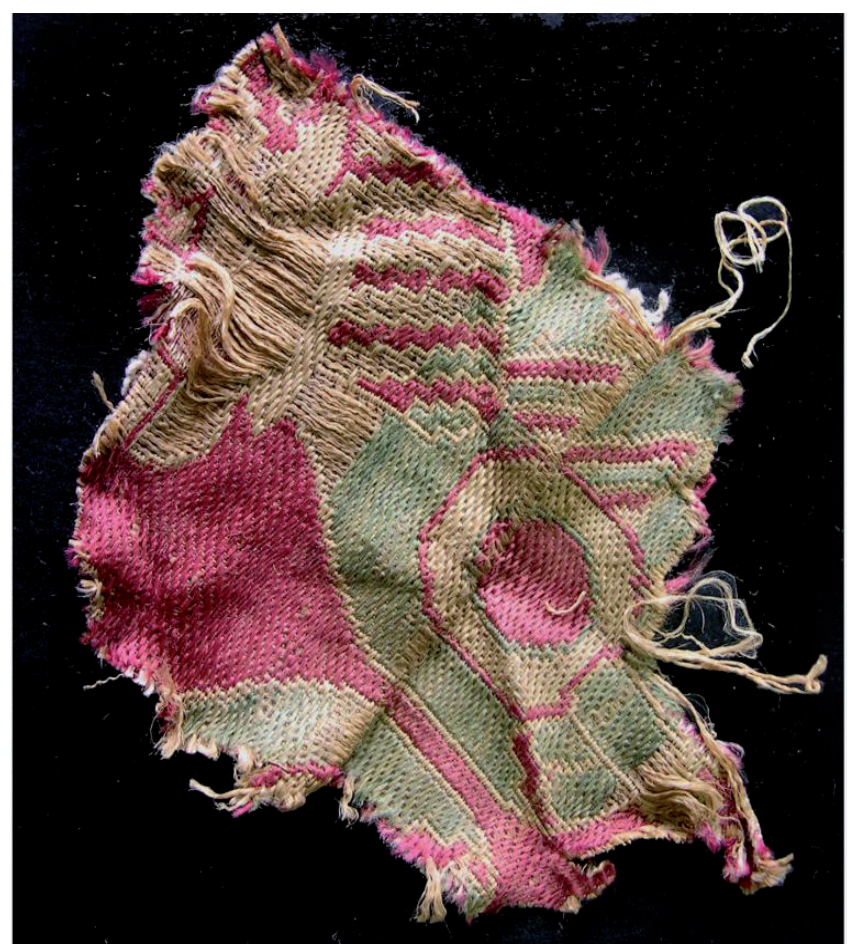

Figura 5.- Samito (ASECT 7.3c), localizado en el interior de la bolsa relicario roja
Por los datos que actualmente disponemos es posible apuntar que la manufactura más probable, tanto del tejido de la bolsa relicario como de los fragmentos que alberga en su interior, no sea Andalusí; aunque actualmente existen pocos análisis de tejidos históricos de este periodo para realmente tener una fuente fiable en la que comparar nuestros resultados analíticos. Nuevos estudios son indispensables para descifrar la combinación de colorantes utilizados en las diferentes zonas geográficas, teniendo en cuenta, además, el intercambio de materiales entre los diferentes centros textiles.

Por otro lado, el colorante rojo de la trama del fragmento tejido en lampás IVDJ 2111 del s.XV-XVI ha dado como resultado cochinilla. Este tejido solamente conserva un orillo, constituido por hilos de seda de dos cabos con torsión en $\mathrm{S}$, mientras que en al-Andalus éstos están formados por cordelinas de lino ${ }^{5}$. Un tejido idéntico, procedente del Metropolitan Museum (MET 12.55.6a,b), conserva ambos orillos con un ancho de telar de $60 \mathrm{~cm}$., una medida muy estrecha si lo comparamos con las empleadas en el lampás nazarí.

El ligamento de fondo es tafetán de hilos dobles, similar al que se emplea a partir del s. XIV en Lucca, Italia. Tanto la medida del ancho del tejido, el tipo de orillo y el resultado del colorante nos recuerda a los terciopelos, que de influencia italiana se están realizando en este periodo en Valencia. Si algunos tejedores musulmanes expulsados de Granada se asientan en Valencia, es una hipótesis que se tejiese en esta ciudad, con un diseño de tradición nazarí pero con clara influencia técnica italiana.

El tinte amarillo encontrado mayoritariamente ha sido identificado como gualda, obtenido de la planta Reseda luteola L. Los principales compuestos detectados, en base a los cuales se ha realizado esta identificación, son los siguientes: luteolina-3'-7-diglucósido, glucósido, luteolin glucósido, luteolina, apigenina y crisoeriol, siendo la luteolina, la apigenina y sus glúcosidos los compuestos mayoritarios.

Los trabajos de investigación recientes indican que los flavonoides luteolina, apigenina y sus glúcosidos, son componentes característicos de, además de la gualda, otros tintes amarillos muy comunes como la serrátula (Serratula tinctoria L.) y la retama, aliaga o genista (Genista spp.). Estos tintes se pueden distinguir por la presencia de otros componentes: el crisoeriol en la gualda; quercetina y kempferol en la serrátula y genisteína en la retama. De esta forma en las muestras donde se ha detectado crisoeriol, el marcador de la Reseda luteola L., el tinte ha sido identificado como gualda; en las muestras donde se ha detectado genisteína y su glucósido, marcadores de la Genista tinctoria L, el tinte ha sido identificado como genista y cuando han sido detectados crisoeriol y genisteína, el tinte ha sido identificado como una mezcla de gualda y genista (Hulme et al. 2004) (Peggie et al. 2008.) 
El fustete (Cotinus coggygria Scop), utilizado desde la antigüedad y según la documentación consultada fue uno de los principales tintes amarillos medievales en la Europa Mediterránea (Hoffenk de Graff 2004). Este tinte es identificado por la presencia de sulfuretina, fisetina y una trihidroxiflavona tipo fisetina (3'-4'-7-trihidroxiflavona). La presencia de fustete mezclado con gualda aporta una tonalidad dorada y en el caso de adicionar además madera de Palo brasil, producirá un tono cobrizo o anaranjado en función de la concentración del colorante rojo.

El fustete también se ha encontrado combinado con un tinte amarillo cuyo principal componente ha sido identificado como kempferol-glucurónido además de otros glicósidos de flavonoides, sin poder identificar la planta de origen. Este tinte ha sido detectado en otras muestras de tejidos (IVJ-2061, ASECT 7.3a, ASECT 6.1c, ASECT 7.3f y al no poder establecer su procedencia se ha designado como "tinte amarillo K-glu".

En la muestra del alma del hilo entorchado del tejido IVDJ 2061, se detecta, a muy baja concentración, además de los taninos un compuesto identificado como rutina y que corresponde a la quercetina-3-O-rutinósido. Este compuesto es característico de distintos tintes amarillos entre los que cabe destacar el tinte obtenido del árbol de las pagodas (Sophora japonica L.) o el tinte conocido como ruda obtenido de la especie Ruta graveolens L., entre otros. De nuevo, al no poder ser identificado inequívocamente, lo designaremos como "tinte amarillo rutina".

En la muestra amarilla correspondiente al cordón de la bolsa relicario roja ASECT 7.3 [figura 2] han sido identificados dos compuestos principales: crocin y dicrocin. Ambos son derivados de la crocetina, principal responsable del color en el azafrán. Este tinte, obtenido de los estigmas de las flores de Crocus sativus L., ha sido utilizado como tinte directo desde la Antigüedad (Ferreira et al. 2004). Aunque se emplearon otros tintes tipo carotenoide, el amarillo dorado del azafrán fue el más famoso y preciado.

En las muestras verdes mayoritariamente se ha detectado gualda e índigo. En el tejido IVDJ 2076 además se ha incorporado otro tinte amarillo, en muy baja concentración, que no ha podido ser identificado.

El color amarillo verdoso del cuerpo del ave del tejido rojo de San Zoilo está compuesto por gualda, índigo y granza, mientras que en la muestra verde, correspondiente al tejido IVDJ 8360, la gualda y el índigo se han mezclado con genista, una planta autóctona de la península ibérica de la que no hemos encontrado referencias, ni documentales ni analíticas, que relacionen este tinte con los tejidos andalusíes.

En la muestra de color verde (ASECT 7.3c) se ha encontrado índigo mezclado con un tinte amarillo cuyos principales componentes han sido identificados como glucósidos de la quercetina, kempferol y ramnetina. Esta composición es característica del tinte amarillo obtenido de diferentes tipos de bayas de numerosas especies del género Rhamnus spp. Es un tinte que ofrece una tonalidad amarillo verdosa al utilizarlo con alumbre y por ello, según la literatura, empleando un fondo de índigo o pastel y posteriormente tiñendo con bayas persas, se obtenía un verde muy estable y brillante. Aunque, es originario del Próximo Oriente, siendo las bayas de Persia las de mejor calidad, las especies de Rhamnus fueron también cultivadas en el sur de Francia, España e Italia y se encuentran, además, en estado silvestre.

En los pardos detectados el tono más rojizo se debe a la combinación de fustete y madera de palo brasil (IVDJ 2075). Una tonalidad más verdosa se origina con la mezcla de indigo, tinte amarillo "K-GLU y taninos (ASECT 7.3f). En el caso del fragmento IVDJ 2076, la combinación de taninos con madera de Palo brasil e índigo nos hace sospechar que el color original fuese negro.

\section{Identificación de mordientes e hilos metálicos}

La aplicación de metal como efecto decorativo en el conjunto estudiado nos indica el alto grado de especialización de los artesanos medievales responsables de su elaboración y su análisis nos puede ayudar, en algunos casos, junto con otros parámetros como la técnica y el colorante empleado, a situar geográficamente la manufactura de los mismos.

Su estudio, con el empleo de diferentes técnicas instrumentales como la microscopía óptica (MO) y la microscopía electrónica de barrido acoplada a un sistema de espectroscopía de rayos $\mathrm{X}$ por dispersión de energías (SEMEDX), proporciona información acerca de la morfología de las fibras y determina la composición elemental de los mordientes empleados en el proceso de tintura, así como los materiales integrantes de los hilos metálicos, información esencial para aportar una aproximación a los procesos de elaboración de los tejidos medievales.

En este corpus podemos apreciar diferentes sistemas de manufactura en la producción de hilos metálicos o métodos de decoración con metal adherido al tejido de base, mencionados en diversos estudios de textiles históricos (Indictor et al. 1989: 171; Indictor 1990: 149; Jaro 1990: 40,42; Hardin and Duffield 1992: 233).

-1. El oro es aplicado con adhesivo al tejido ya elaborado. (ASECT 7.3) [imagen 2].

- 2. El hilo metálico está formado por una lámina metálica que trabaja como trama espolinada en determinados motivos decorativos (IVDJ 2088).

- 3. La trama decorativa está formada por una lámina de plata dorada que envuelve, en forma de espiral, un hilo de alma de seda (IVDJ 2076; IVDJ 8360 e IVDJ 2122). En los dos 
primeros tejidos el resultado del análisis indica que la plata ha sido dorada únicamente por la cara externa. [figura 6].

Las placas de plata se doraban con lámina de oro y se pulían. Posteriormente eran golpeadas o batidas hasta obtener un grosor, en este caso, de 11 a $26 \mu \mathrm{m}$, y a continuación se cortaban en estrechas bandas de 180-280 $\mu \mathrm{m}$. (Darrah 1987: 211-212; Hardin \& Duffield 1992: 239-242; Járó 1990: 47-48; Hacke et al. 2004: 415-416). El resultado del corte efectuado con una herramienta especial produce bordes angulosos y estriados.

En este caso se detecta un alto contenido en cobre, que puede corresponder con la técnica de manufactura descrita por el monje Benedictino Teófilo en el s. XII, donde el oro se suelda con la plata con la ayuda de sales de cobre. (Hawthorne and Smith, 1979; Bergstrand \& Hedhammar 2006: 12; Járó et al. 1993: 121).

- 4. En el fragmento IVDJ 2122, datado en el s. XIV-XV y de procedencia turca, pues lleva el nombre del príncipe turco Murad I (1359-1383), según el epigrafista egipcio A. Dokmak, el resultado del análisis de la lámina difiere del caso anterior en que la plata está dorada por la cara externa e interna, con un espesor de $10-15 \mu \mathrm{m}$ y un ancho de $200 \mu \mathrm{m}$.

En este caso, se parte de un alambre de plata que es cubierto por una lámina de oro. Una vez adherido el oro mediante calor y pulido, se reduce la sección del alambre haciéndolo pasar a través de un orificio cónico de una herramienta denominada hilera, que va disminuyendo de diámetro hasta obtener el grosor deseado. Esta varilla fina es aplanada en forma de tiras pasándola a través de un rodillo, cuyo resultado es una banda homogénea de bordes redondeados que presenta estrías longitudinales (Hardin, I. R \& Duffield, F. J. 1986: 239-242; Járó et al. 1993: 121; Járó \& Thot 1993: 176; Hacke et al. 2004: 415-416).

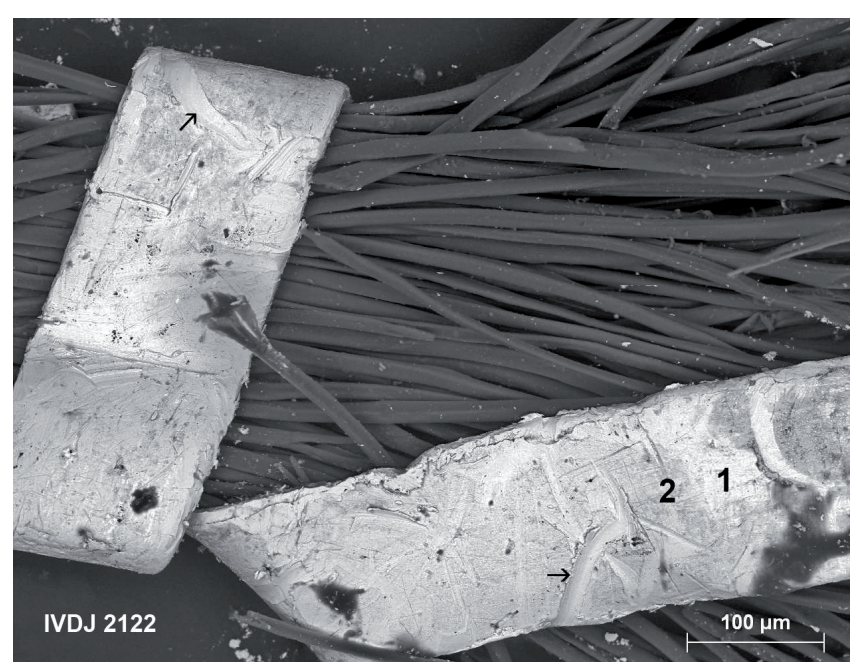

Figura 6.- Muestra IVDJ 2122. Imagen SEM de un entorchado correspondiente a una lámina metálica de plata dorada alrededor de un alma de seda. Obsérvese la delgada lámina de oro (1) sobre la plata (2) y las excoriaciones superficiales en el metal (flechas).
- 5. La mayoría de los hilos estudiados están compuestos por tiras orgánicas plateadas y/o doradas enrolladas sobre un alma de seda o material celulósico, denominados hilos metálicos orgánicos (Indictor et al. 1989: 171; De Reyer et al. 2002: 122). Esta forma de trabajo consume menos metal, por lo tanto, es más económica y flexible ((Járó et al. 1993:123; Járó 2004: 5051; Karatzani et al. 2009: 100), lo que implica que se adapte mejor a las estructuras complejas que se elaboran en este periodo y se produzcan menos roturas en las finas urdimbres durante el trabajo en el telar, pero el inconveniente es que se deterioran con mucha más facilidad. El origen de estos hilos posiblemente sea China, por el hallazgo reciente de este hilo metálico orgánico en el templo Famen que data de la dinastía Tang (618-907 d.C.)(Karatzani et al. 2009: 100).

El término de sustrato orgánico se refiere a un material proteico: cuero, pergamino o vísceras procedentes del intestino o vejiga animal, o celulósico: papel. Estos materiales son cubiertos con oro o plata dorada y se enrollan sobre un hilo de alma, denominados en ocasiones como "oro Bizantino" u "oro de Chipre" en función de su procedencia y composición (Jaró 1990: 50; Darrah 1987: 211; Járó et al. 1993: 123)

En al-Andalus tenemos constancia del empleo de estos hilos entorchados con alma de seda en el s.X-XI (almaizar de Hixam II, tiraz de Colls). La materia orgánica es piel en una primera etapa, con un alto contenido en oro, que irá aumentando la proporción de plata a finales del s. XIII hasta desaparecer en algunos tejidos a mediados del s. XIV [figura 7].

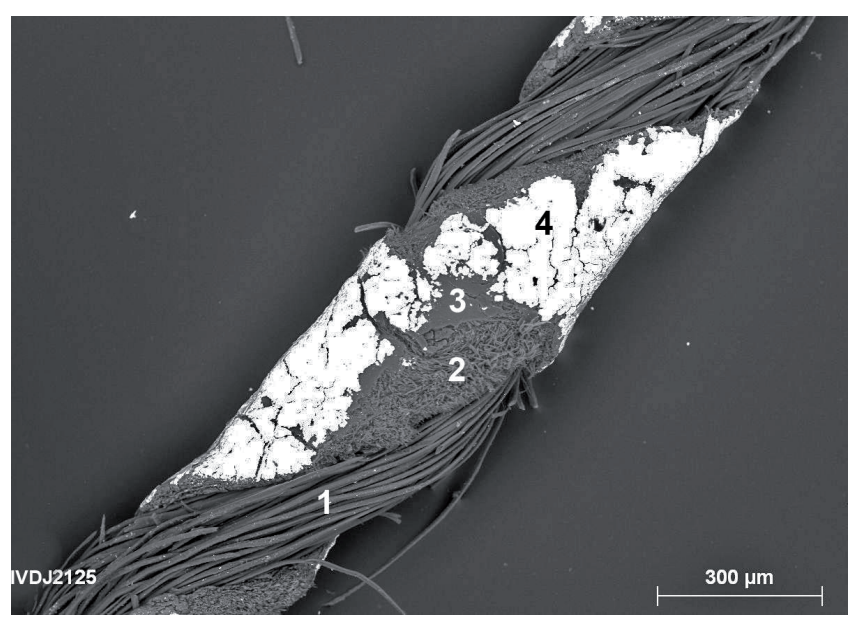

Figura 7.- Muestra IVDJ 2125. Imagen SEM correspondiente a un entorchado metálico en el que se distingue claramente su estructura: alma de seda (1), cubierta orgánica de piel (2), delgada capa de adhesivo (3) y lámina de oro en superficie (4).

Por el contrario, en los tejidos mudéjares del siglo XIII el alma es de lino o ramio y el sustrato orgánico intestino animal. En ambos casos la composición fundamental es el colágeno, dispuesto de diferente manera dependiendo del tejido de origen.

En la sección transversal de 3 patrones: cuero, pergamino e intestino, efectuados por MO con lámpara de Wood, 
tanto en el pergamino como en el intestino, la intensa fluorescencia azulada se vincula con su naturaleza proteica, el colágeno. En el cuero, la tonalidad parda está relacionada con la presencia de taninos empleados en el curtido de la piel.

Las fibras de colágeno se orientan de diferente manera en función de la procedencia del material. En el intestino éstas se disponen paralelas mientras que en el pergamino, y sobre todo en el cuero, además de apreciarse las depresiones de los folículos pilosos, la orientación es más aleatoria con la formación de una compleja red de fibrillas entrelazadas, que en el pergamino tienden a organizarse en el proceso de estirado en un bastidor, pero sin llegar nunca al estado estructurado de las vísceras (De Reyer et al 2002: 122-123).

Al tratar estos patrones con fuchina, reactivo con gran afinidad por las proteínas, tanto el intestino como el pergamino se tiñen de rojo. En el caso del cuero curtido con taninos, la tinción queda enmascarada por la tonalidad parda producida por la presencia de taninos.

Con los análisis efectuados hasta el momento mediante SEM/EDX, podemos precisar que en 4 de las muestras de piel se ha detectado un alto contenido de $\mathrm{Al}$ y $\mathrm{K}$, lo que sugiere que la piel ha sido tratada con alumbre.

En siete tejidos se ha determinado los componentes añadidos al hilo entorchado. A través del análisis composicional ha sido posible diferenciar claramente las muestras de cuero de las de intestino. Las primeras presentan significativas cantidades de taninos, con el ácido elágico como compuesto mayoritario.
En las muestras de piel se observa una fina película entre el metal y el sustrato orgánico, que indica la presencia de un adhesivo. Al tratar las muestras con fuchsina ácida, esta capa de adhesivo se tiñe de rojo, lo que se asocia con la naturaleza proteica del material. Los posibles adhesivos proteicos utilizados en época medieval son la cola animal o el huevo, pero la fluorescencia tanto de la cola como la de la clara de huevo es azul y amarillo anaranjado, en el caso de incorporar la yema. La tonalidad tan intensa que se aprecia en varias de las muestras podría señalar que el adhesivo ha sido coloreado. [figura 8].

En el análisis cromatográfico de los cinco entorchados de piel se ha identificado gualda en dos de ellos y un colorante amarillo en otros dos, donde están presentes la luteolina, apigenina y sus glucósidos, pero carece de crisoeriol, marcador de la Reseda Luteola. Si la presencia del colorante amarillo procede del adhesivo, podría tener como finalidad evitar reflejos pardos en el oro al transparentarse el color del la piel curtida.

Otro compuesto que se observa en una de las muestras del s. XIV es una antraquinona, de procedencia desconocida y trazas de cochinilla e índigo en el tejido del arca ASECT 6.1c.

En la sección transversal de varias muestras de piel, se advierten manchas rojas en la zona superior del metal, en la zona de unión del metal con la piel y, en ocasiones, esta coloración impregna parte de la piel [figura 4]. Intentar interpretar estos resultados nos lleva a proponer la posibilidad de que sobre el metal se aplicase una veladura coloreada de origen proteico que, por un lado, protegiese la lámina y, por otro, crease una distinción cromática que se integrase con la decoración del tejido.

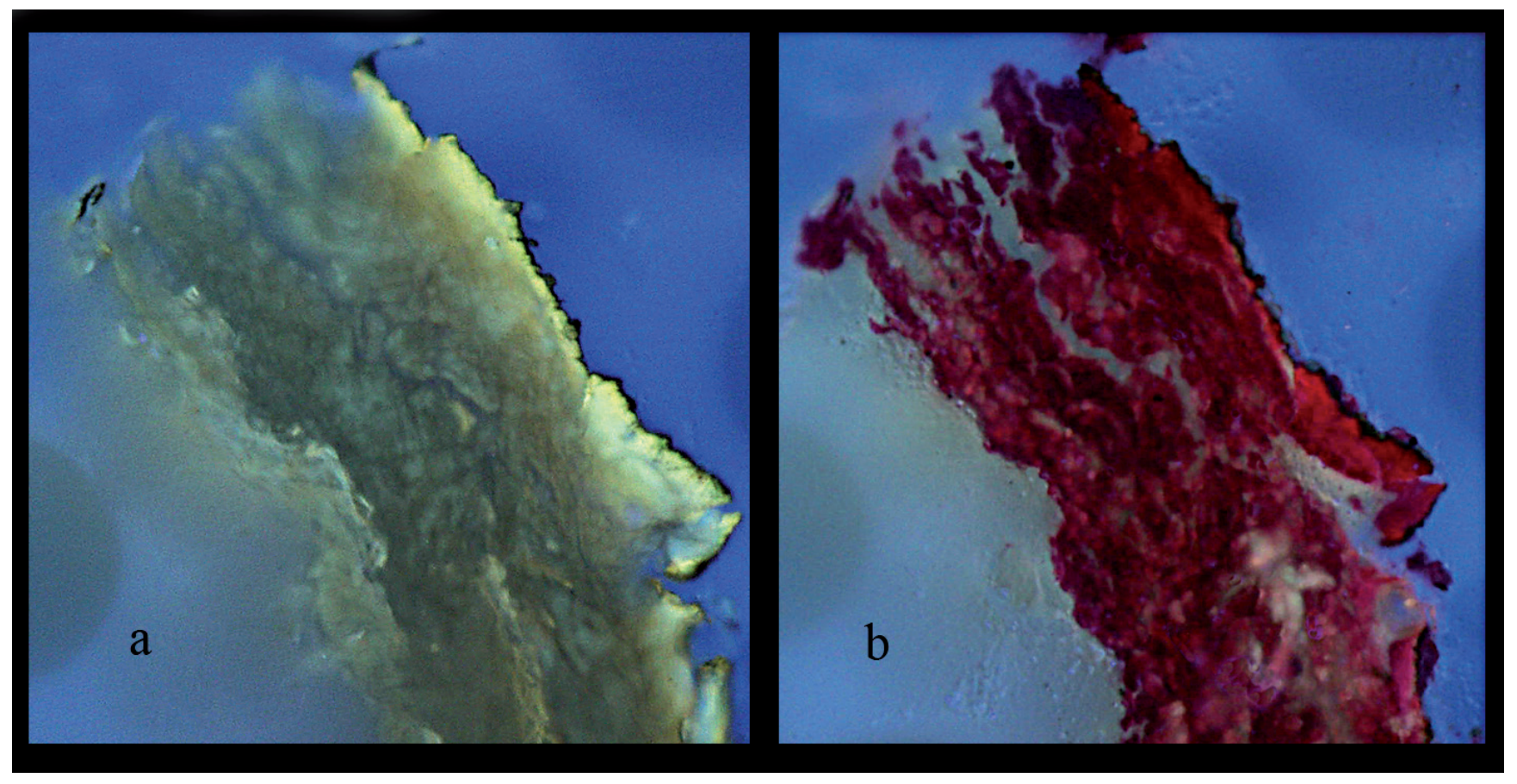

Figura 8.- Microfotografía de un sustrato orgánico de piel dorada obtenida con lámpara de Wood (a). La misma muestra teñida con fuchsina ácida, que permite detectar la presencia del material proteico (b). 
En las dos muestras de intestino analizadas han sido claramente identificados ácidos grasos procedentes de una substancia grasa que puede ser de origen vegetal (aceite no secativo) o animal (huevo, manteca, lanolina etc). En este caso no se visualiza una capa entre el metal y el sustrato, posiblemente la propia gelatina del intestino en húmedo es la que sirva de adhesivo (Indictor et al. 1989: 178) [figura 9].

Del estudio efectuado en los hilos metálicos y en función de los resultados obtenidos, podemos concluir diferentes formas de elaboración de los mismos dependiendo de la zona geográfica:

- 1. En Castilla, durante el siglo XIII, el metal empleado en la elaboración del hilo entorchado consta de una lámina de plata, dorada solamente por una de las caras, que posteriormente era batida y cortada en tiras.

Estos tejidos se van a caracterizar también por el empleo de una técnica sencilla, con telares estrechos y donde la genista es uno de los tintes amarillos empleados, mientras que no existe referencia alguna en cuanto a su uso en alAndalus.
- 2. En territorio cristiano realizado por mudéjares, y durante el s. XIII, se tejieron samitos denominados filosedas con hilos entorchados formados por un sustrato orgánico de intestino animal, metalizado con plata dorada que envuelve, en forma de espiral, un hilo de alma de fibra celulósica.

Este tipo de tejido es considerado por algunos autores como italiano, aunque es posible que fuesen tejidos indistintamente en ambos países por tejedores islámicos. En ninguno de los tejidos del territorio hispano se ha identificado quermes, tinte muy apreciado y costoso exclusivo de al-Andalus, por los resultados que hasta ahora hemos obtenido de la península.

- 3. En al-Andalus, el hilo metálico está formado por piel dorada que irá aumentando el contenido de plata al final del periodo almohade, hasta ser sustituido, en algunos casos, por hilo de seda de color amarillo en el periodo nazarí. La aplicación del oro mediante adhesivo es en lámina, excepto en dos muestras donde su aplicación en ambos casos es en polvo, en el tejido B 23780, procedente de Irán o Irak; y en IVDJ 2061, fragmento del sepulcro del infante don Felipe (1274), un tipo de tejido que suscita discrepancias en cuanto

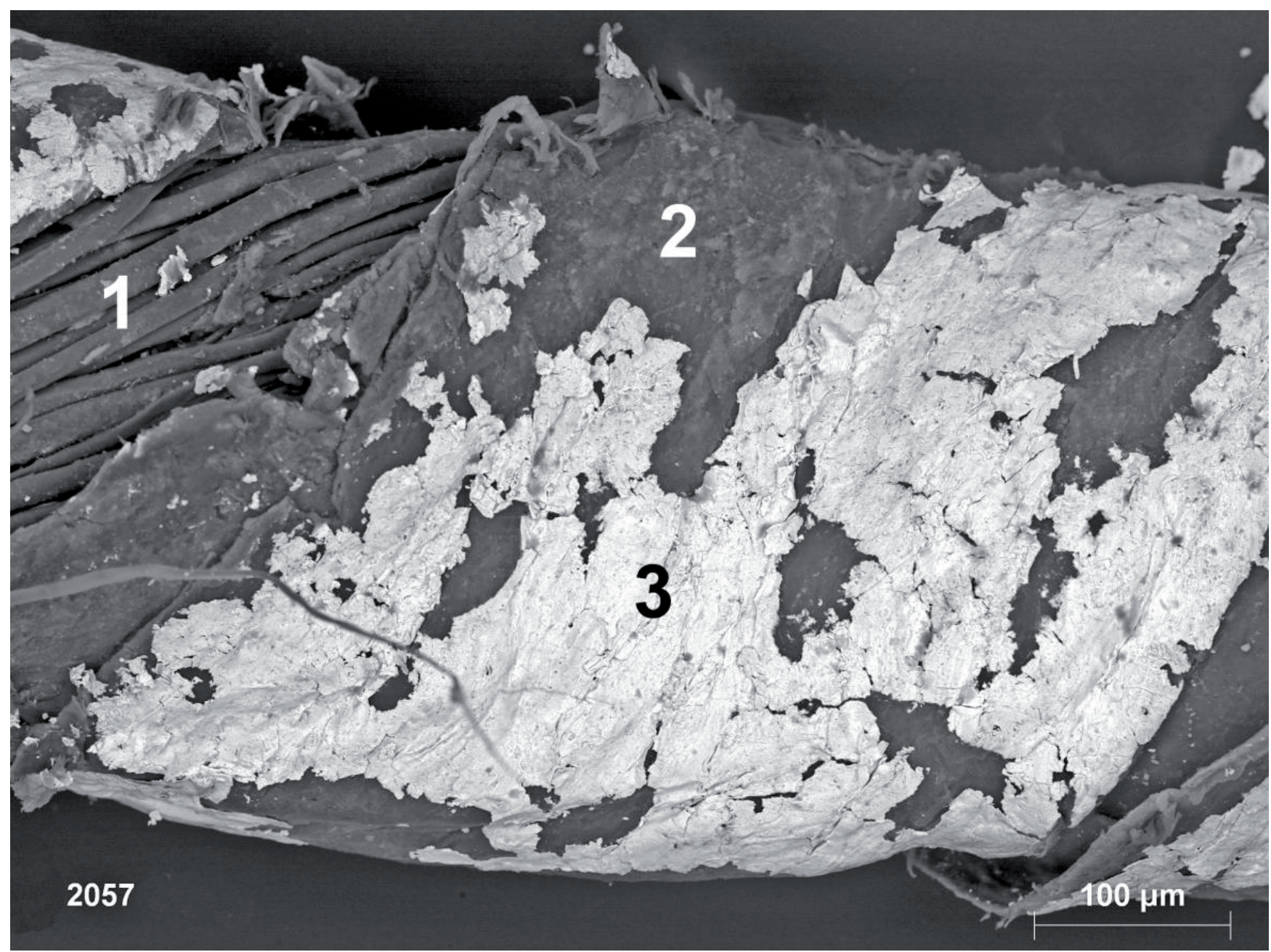

Figura 9.- Muestra IVDJ 2057. Imagen SEM de un entorchado con alma de seda (1), cubierta orgánica flexible de tripa (2) y lámina de plata dorada (3). 
a su origen español no italiano (De Jongue \& Verhecken Lammens 1999: 121,135; Cardon 1999: 139, 153-155).

Este fragmento IVJ 2061 también presenta una particularidad en dos de los tintes empleados. Por un lado el denominado "Tinte amarillo K-glu", identificado en varias muestras de la bolsa relicario roja ASECT 7.3, que como hemos indicado anteriormente no parece tenga su origen en al-Andalus, en cuanto al tinte, pero no hay duda de su ejecución andalusí y otro tinte amarillo, en muy baja concentración, que no ha podido ser identificado y se ha designado como"Tinte amarillo rutina".

La aportación de nuevos análisis de tejidos que puedan contribuir a un conocimiento más profundo de los diferentes centros textiles medievales, la evolución de la tecnología y la transferencia de conocimiento entre las diferentes culturas, es un desafío necesario en un país con un patrimonio textil privilegiado.

\section{Notas}

[1] Instituto de Valencia de Don Juan, Madrid (IVDJ); Arca de San Eugenio, Catedral de Toledo (ASECT); Hispanic Society of America, Nueva York (HSA); Centre de Documentació i Museu Textil de Terrassa, Barcelona (CDMT); Túnica de San Ramón, Roda de Isábena, Huesca (TSR); Fernando de la Cerda, Monasterio de Santa María la Real de Huelgas, Burgos (FDC); Tiraz de Colls, Ermita de Nuestra Señora de Colls, Museo de Huesca (T-146); Museo Textil y de la Indumentaria, Barcelona (MTIB); Real Monasterio de San Zoilo, Carrión de los Condes, Palencia (HMP); San Pedro de Osma, catedral de Burgo de Osma, Soria; Aljuba del Infante García, Monasterio de San Salvador de Oña, Burgos (AIG); Museo Lázaro Galdiano, Madrid (MLG).

[2] Algunas de estas piezas (HMP, San Pedro de Osma y AIG) fueron analizadas con motivo de su restauración en el CCRBC de la Junta de Castilla y León.

\section{[3] Victoria and Albert: Inv. 39-1896}

[4] La cochinilla americana comienza a utilizarse en la península en el siglo XVI.

[5] Tres o cuatro hilos gruesos formados por la torsión en $\mathrm{S}$ de varios cabos de lino, que impedían la deformación de los bordes durante el proceso de tejeduría.

[6] No se ha podido tomar muestra del hilo metálico

\section{Bibliografía}

BERGSTRAND, M. \& HEDHAMMAR, E. (2006). “European Metal Threads in Swedish Churches 1600-1751. Construction and conservation", Studies in conservation, 51: 11-28.

BORREGO, P., SALADRIGAS, S., ANDRES-TOLEDO, M.A. (2014). Technical and stylistic study of two complete medieval cloths found in Carrión de los Condes, Spain. Textiles, basketry and dyes in the ancient Mediterranean world: Proceding of the Vth Purpureae Vestes International Symposium, Montserrat: 163- 170.

CARDON, D. (1999). “D' Espagne á L'Italie. Hypothése concernant un grouped soieries médiévales á fond de losanges liserés et bandes de samit façonné", Techniques \& Culture, 34, Soieries médiévales: 122-139.

DARRAH, J.A. (1987). "Metal Threads and Filaments", Recent Advances in the Conservation and Analysis of Artifacts, London Summer School Press, University of London: 211-221.

DE GRAFF, J.H. (2006). "Master dyers to the Court of Sicily", To dye anything that you want to dye. The "art of dyeing" and its significance for the understanding of historic textiles and their condition, Amsterdam: Universiteit van Amsterdam: 123-133.

DE JONGUE, D., VERHECKEN LAMMENS, A. (1999). “Une sederie losangée à bande de samit façonné". Techniques \& Culture, Soieries médiévales 34 : 122-135.

DE REYER, D., JEANTET, A., PILBOUT, S. (2002). "Les lamelles des fils metalliques organiques dans les textiles médiévaux: approche méthodologique de leur origine biologique", Studies in conservation, 47: 122-133.

FERREIRA, E. S. B., HULME, A. N., McNAB, H., QUYE, A. (2004) “The natural constituents of historical textile dyes". Chem. Soc. Rev., 33: 329-336.

HACKE, A.M., CARR, C.M., BROWN, A., HOWELL, D. (2004). "Characterization of metal threads in Renaissance tapestries". Scientific Analysis of Ancient and Historic Textiles: Informing Preservation, Display and Interpretation, AHRB Research Centre for Textiles Conservation and Textiles Studies First Annual Conference, Textile Conservation Centre, Winchester Campus, University of Southampton, UK, 13-15 July, ed R. Janaway and P. Wyeth, Archetype Publications: 71-78.

HARDIN, I. R., DUFFIELD, F. J. (1986). “Characterization of Metallic Yarns in Historic Persian Textiles by Microanalysis", Historic Textile and Paper Materials, American Chemical Society: 230-25.

HAWTHORNE, J.G., SMITH, C.S. (1979). Theophilus: On Divers Arts. The Foremost Medieval Treatise on Painting, Glassmaking and Metalwork. New York: Dover Publications: 1-216.

HOFENK DE GRAAFF, J. (2004). The Colourful Past. Origin, Chemistry and Identification of Natural Dyestuff, Switzerland: Abegg-Stiftung, London: Archetype Publications Ltd.

HOKE, E., PETRASCHEK-HEIM, I. (1977). "Microprobe Analysis of Gilded Silver Threads from Mediaeval Textiles", Studies in Conservation, 22: 49-62.

HULME, A.N., McNAB, H., PEGGIE, D.A., QUYE, A. (2004). "The application of liquid chromatography-mass spectrometry and accelerated light ageing for the analytical identification of yellow flavonoid dyes in historical tapestries", Scientific Analysis 
of Ancient \& Historic Textiles. Post-prints of first AHRC Research Centre international conference: 208-216.

INDICTOR, N., KOESTLER, R. J., BLAIR, C., WARDWELL, A. E. (1988). "The Evaluation of Metal Wrappings from Medieval Textiles Using Scanning Electron Microscopy-Energy Dispersive X-Ray Spectrometry", Textile History, 19(1): 3-19.

INDICTOR, N., KOESTLER, R. J., WYPYSKI, M., WARDWELL A. E. (1989). "Metal Threads Made of Proteinaceous Substrates Examined by Scanning Electron Microscopy Energy Dispersive X-Ray Spectrometry", Studies in Conservation, 34: 171-182.

INDICTOR, N., BLAIR, C. (1990). “The Examination of Metal from Historic Indian Textiles Using Scanning Electron MicroscopeEnergy Dispersive X-Ray Spectrometry", Textile History, 21(2): 149-163.

JÁRÓ, M. (1990). “Gold embroidery and fabrics in Europe: XIXIV centuries", Gold Bulletin, 23(2): 40-57.

JÁRÓ, M., GONDAR, E., TÓTH, A.L. (1993). "Technical revolutions in producing gold threads used for European textile decoration". Outils et ateliers d'orfevres des temps anciens. Antiquités Nationales, Mémoire 2, Société des Amis du Musée des Antiquités Nationales et du château de SaintGermain-en-Laye: 119-124.

JÁRÓ, M. (1998). "Differences in manufacturing technique, usually neglected, with the description of mediaeval metal threads made of metal coated organic material. Some remarks on the basis of the results of scientific examinations", in R. Varoli-Piazza (ed): 141-148

KARATZANI, A., REHREN, T., ZHIYONG, L. (2009). “The metal threads from the silk garments of the Famen Temple", Restaurierung und Archäologie 2: 99-109.

MANTZOURIS, D, KARAPANAGIOTIS, I., VALIANOU, L., PANAYIOTOU, C. (2011). "HPLC-DAD-MS analysis of dyes identified in textiles from Mount Athos", Analytical and Bioanalytical Chemistry, 399(9): 3065-79.

MELO, M. J. (2009). "History of natural Dyes in the Ancient mediterranean World" en BECHTOLD, Thomas; MUSSAK, Rita (ed.), Handbook of Natural Colorant", Capitulo 1, John Wiley \& Sons, Ltd.

MEYER, L. (2000). "Textiles of Islamic Spain", Medieval Textile Study Group, 24: 3-9.

PARTEARROYO, C. (1992). "Cortina nazarí" Al-Andalus. Las Artes islámicas en España. Madrid, n 99: 338-339.

PEGGIE. D.A., HULME, A. N., McNAB, H., QUYE, A. (2008). "Towards the identification of characteristic minor components from textiles dyed with weld (Reseda luteola L.) and those dyed with Mexican cochineal (Dactylopius coccus Costa)", Microchim Acta 162: 371-380.
PIRENNE, F. (2005). “Tissus précieux au Trésor de Liège”. Trésors des catedrales d'Europe. Liège à Beaune: 128-142.

ROQUERO, A. (2008). "Tintorería medieval en Europa", Ingeniería medieval en España, Fundación Juanelo Turriano \& Ministerio de Fomento, Madrid: 234-243.

SALADRIGAS CHENG, S. (1996). "Los tejidos en al-Andalus. Siglo IX-XVI. Aproximación técnica", España y Portugal en las rutas de la seda. Diez siglos de producción entre Oriente y Occidente. Barcelona: Universitat de Barcelona, 74-98.

SHEPHERD D. (1957). "A dated hispano-Islamic silk". Ars Orientalis II: 373-381.

VV.AA. (2005). "Tejidos Hispano-musulmanes", Bienes Culturales. Revista del Instituto del Patrimonio Histórico Español, 5.

VIAL, G., FAYARD, P. (1995). "Anhang Technischer Katalog: chasuble, dalmatique et chape de Saint Valère", FluryLemberg et Illek: 236-255.

WOUTERS, J., VERHECKEN LAMMENS, A. (1989) "The coccid insect dyes: HPLC and computerized diode-array analysis of dyed yarns", Studies in Conservation, 34: 189-200. 


\section{ANEXO}

Arca de San Eugenio, Catedral de Toledo (ASECT); Instituto de Valencia de Don Juan, Madrid (IVDJ); Hispanic Society of America, Nueva York (HSA); Centre de Documentació i Museu Textil de Terrassa, Barcelona (CDMT); Museo Textil y de la Indumentaria, Barcelona (MTIB); Real Monasterio de San Zoilo, Carrión de los Condes, Palencia (HMP); Túnica de San Ramón, Roda de Isábena, Huesca (TSR); Fernando de la Cerda, Monasterio de Santa María la Real de Huelgas, Burgos (PFC); Tiraz de Colls, Ermita de Nuestra Señora de Colls, Museo de Huesca (T-146); San Pedro de Osma, catedral de Burgo de Osma, Soria; Museo Lázaro Galdiano, Madrid (MLG).

\section{TABLA 1: ANÁLISIS TÉCNICO DEL TEJIDO}

\begin{tabular}{|c|c|c|c|c|c|}
\hline $\begin{array}{l}\text { TEJIDO/ } \\
\text { DATACIÓN/ } \\
\text { ORIGEN }\end{array}$ & $\begin{array}{l}\text { MUSEO/ } \\
\text { No INV/ } \\
\text { /TÉCNICA } \\
\end{array}$ & $\begin{array}{l}\text { TEJIDO/ } \\
\text { DATACIÓN/ } \\
\text { ORIGEN }\end{array}$ & $\begin{array}{l}\text { MUSEO/ } \\
N^{\circ} \text { INV/ } \\
\text { /TÉCNICA } \\
\end{array}$ & $\begin{array}{l}\text { TEJIDO/ } \\
\text { DATACIÓN/ } \\
\text { ORIGEN }\end{array}$ & $\begin{array}{l}\text { MUSEO/ } \\
\text { No INV/ } \\
\text { /TÉCNICA } \\
\end{array}$ \\
\hline $\begin{array}{l}\text { Fragmento del } \\
\text { interior del arca de } \\
\text { San Eugenio. } \\
\text { s. XII. Bizantino o } \\
\text { siciliano? }\end{array}$ & $\begin{array}{c}\text { ASECT 6.1c } \\
\text { ASECT 7.3a } \\
\text { Tafetán y } \\
\text { tafetán doble } \\
\text { (técnica de } \\
\text { tapicería) }\end{array}$ & $\begin{array}{l}\text { Pragmento del } \\
\text { Fran del Arca de } \\
\text { interior de } \\
\text { San Eugenio. } \\
\text { s. XII. Andalusí. }\end{array}$ & $\begin{array}{c}\text { ASECT } 7.2 \\
\text { Lampás efecto de } 2 \\
\text { tramas lanzadas y } 1 \\
\text { trama espolinada, } \\
\text { fondo tafetán } \\
\text { irregular } \\
(3,3,2,1,2,3 . .)\end{array}$ & $\begin{array}{l}\text { Bolsa relicario. Arca de } \\
\text { San Eugenio. } \\
\text { s. XII. Bizantino o } \\
\text { siciliano? }\end{array}$ & $\begin{array}{c}\text { ASECT } 7.3 \\
\text { Sarga } \\
\text { (estampada) de } \\
3(2 / 1), \\
\text { sentido trama, } \\
\text { dirección S }\end{array}$ \\
\hline $\begin{array}{l}\text { Fragmento del } \\
\text { interior de la bolsa } \\
\text { 7.3. Arca de San } \\
\text { Eugenio. s. XII. } \\
\text { Bizantino o } \\
\text { siciliano? }\end{array}$ & $\begin{array}{l}\text { ASECT 7.3b } \\
\text { Tafetán } \\
\text { tornasolado }\end{array}$ & $\begin{array}{l}\text { Fragmento del } \\
\text { interior de la bolsa } \\
\text { 7.3. Arca de San } \\
\text { Eugenio. s. XII? } \\
\text { Bizantino } \\
\text { siciliano? }\end{array}$ & $\begin{array}{c}\text { ASECT 7.3c } \\
\text { Samito efecto de } \\
\text { tres tramas lanzadas } \\
\text { (la tercera a } \\
\text { cambios), con base } \\
\text { de sarga de } 3(2 / 1) \text {, } \\
\text { efecto trama, } \\
\text { dirección S }\end{array}$ & $\begin{array}{l}\text { Forro del fragmento } \\
\text { 7.3c. Arca de San } \\
\text { Eugenio. s. XII. } \\
\text { Bizantino o siciliano? }\end{array}$ & $\begin{array}{l}\text { ASECT 7.3d } \\
\text { Tafetán }\end{array}$ \\
\hline $\begin{array}{l}\text { Bolsa relicario de } \\
\text { San Dionisio. } \\
\text { Interior de la bolsa } \\
\text { 7.3. Arca de San } \\
\text { Eugenio. } \\
\text { s. XII. Bizantino o } \\
\text { siciliano? }\end{array}$ & ASECT 7.3e & $\begin{array}{l}\text { Bolsa relicario de } \\
\text { San Eugenio. } \\
\text { Interior de la bolsa } \\
\text { 7.3. Arca de San } \\
\text { Eugenio. s. XII. } \\
\text { Bizantino } \\
\text { siciliano? }\end{array}$ & ASECT 7.3f & $\begin{array}{l}\text { Fragmento del interior } \\
\text { de la bolsa 7.3. Arca de } \\
\text { San Eugenio. s. XII. } \\
\text { Bizantino o siciliano? }\end{array}$ & $\begin{array}{l}\text { ASECT 7.3i } \\
\text { Tafetán liseré }\end{array}$ \\
\hline $\begin{array}{c}\text { Hilos sueltos del } \\
\text { interior de una de } \\
\text { las bolsas del arca } \\
\text { de San Eugenio, s. } \\
\text { XII? }\end{array}$ & $\begin{array}{l}\text { ASECT 9; } \\
\text { ASECT9A; } \\
\text { ASECT 9B; } \\
\text { ASECT 9C; } \\
\text { ASECT 9D } \\
\text { ASECT 9E }\end{array}$ & $\begin{array}{l}\text { Fragmento de la } \\
\text { capa del Abad } \\
\text { Biure, s. XIII. } \\
\text { Mudéjar }\end{array}$ & $\begin{array}{c}\text { IVDJ } \mathbf{2 0 5 7} \\
\text { Samito efecto de } 3 \\
\text { tramas lanzadas, } \\
\text { fondo de sarga de } 3 \text {, } \\
\text { dirección S }\end{array}$ & $\begin{array}{c}\text { Sepulcro del infante D. } \\
\text { Felipe, s. XIII. } \\
\text { Andalusi? }\end{array}$ & $\begin{array}{l}\text { IVDJ } 2061 \\
\text { Bayadera: } \\
\text { Tafetán, } \\
\text { tafetán liseré } \\
\text { efecto de una } \\
\text { trama y doble } \\
\text { cara trama, } \\
\text { efecto de dos } \\
\text { y tres tramas }\end{array}$ \\
\hline
\end{tabular}




\begin{tabular}{|c|c|c|c|c|c|}
\hline $\begin{array}{c}\text { Capa del Infante Felipe, } \\
\text { s. XIII. } \\
\text { Andalusí }\end{array}$ & $\begin{array}{l}\text { IVDJ } 2069 \\
\text { Taqueté } \\
\text { efecto de tres } \\
\text { tramas } \\
\text { lanzadas, la } 3^{\mathrm{a}} \\
\text { interrumpida, } \\
\text { fondo tafetán }\end{array}$ & 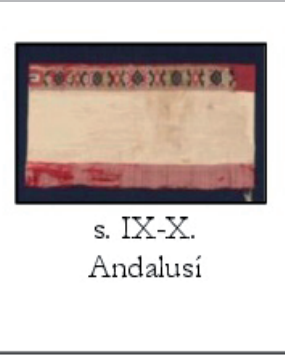 & $\begin{array}{l}\text { IVDJ } 2070 \\
\text { Tafetán y } \\
\text { tafetán doble } \\
\text { (técnica de } \\
\text { tapicería) }\end{array}$ & $\begin{array}{l}\text { Trave } \\
\text { Franja del Pirineo, } \\
\text { s. X. Andalusi }{ }^{1}\end{array}$ & $\begin{array}{l}\text { IVDJ } 2071 \\
\text { Tafetán } \\
\text { irregular }(1,2 \circ \\
3 \text { hilos) } \\
\text { (técnica de } \\
\text { tapicería) }\end{array}$ \\
\hline $\begin{array}{l}\text { Fragmento de velo o } \\
\text { cendal, s.XIII. Reino } \\
\text { cristiano }\end{array}$ & $\begin{array}{l}\text { IVDJ } 2075 \\
\text { Tafetán con } \\
\text { efecto de } \\
\text { perdido por } \\
\text { trama }\end{array}$ & $\begin{array}{l}\text { Fragmento de velo } \\
\text { o cendal, s. XIII. } \\
\text { Reino cristiano }\end{array}$ & $\begin{array}{l}\text { IVDJ } 2076 \\
\text { Tafetán con } \\
\text { efecto de } \\
\text { perdido por } \\
\text { trama }\end{array}$ & $\begin{array}{l}\text { s. XI-XII. } \\
\text { Andalusí? }\end{array}$ & $\begin{array}{c}\text { IVDJ } 2077 \\
\text { Samito efecto } \\
\text { de cuatro } \\
\text { tramas (a } \\
\text { cambios e } \\
\text { interrumpidas), } \\
\text { con base de } \\
\text { sarga de } 3 \text {, } \\
\text { efecto trama, } \\
\text { dirección S }\end{array}$ \\
\hline $\begin{array}{c}\text { Alba del Abad Biure, s. } \\
\text { XI. } \\
\text { Andalusí }\end{array}$ & $\begin{array}{l}\text { IVDJ } 2081 \\
\text { Tafetán doble } \\
\text { (técnica de } \\
\text { tapicería) }\end{array}$ & 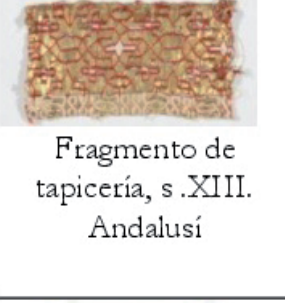 & $\begin{array}{l}\text { IVDJ } 2082 \\
\text { Tafetán doble } \\
\text { (técnica de } \\
\text { tapicería) }\end{array}$ & $\begin{array}{c}\text { ats } \\
\text { s. XIII. } \\
\text { Mudéjar o italiano. }\end{array}$ & $\begin{array}{c}\text { IVDJ } 2083 \\
\text { MLG } 1723 \\
\text { Samito efecto } \\
\text { de tres tramas } \\
\text { lanzadas }\end{array}$ \\
\hline $\begin{array}{l}\text { Fragmento de tejido, s. } \\
\text { XIV. } \\
\text { Andalusi }\end{array}$ & $\begin{array}{l}\text { IVDDJ } 2084 \\
\text { Lampás efecto } \\
\text { de } 1 \text { trama } \\
\text { lanzada. Raso } \\
5 \text { escalonado } \\
3 .\end{array}$ & $\begin{array}{l}\text { Fragmento de } \\
\text { tejido, s. XIV. } \\
\text { Andalusi }\end{array}$ & $\begin{array}{l}\text { IVDJ } 2085 \\
\text { Lampás efecto } \\
2 \text { tramas } \\
\text { lanzadas, la } 2^{\mathrm{a}} \\
\text { interrumpida. } \\
\text { Fondo raso de } \\
5 \text { escalonado } 3\end{array}$ & s. XII-XIII. Andalusí & $\begin{array}{c}\text { IVDJ } 2086 \\
\text { Taqueté efecto } \\
\text { de tres tramas } \\
\text { lanzadas con } \\
\text { base de tafetán }\end{array}$ \\
\hline 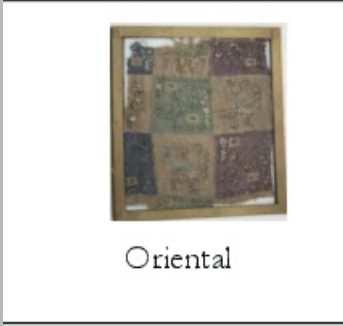 & $\begin{array}{l}\text { IVDJ } 2088 \\
\text { Tafetán efecto } \\
\text { de perdido } \\
\text { ( } 2 \text { tramas } \\
\text { espolinadas y } \\
\text { a cambios) }\end{array}$ & $\begin{array}{l}\text { Pragmento de tejido } \\
\text { del s. XIV. } \\
\text { Andalusi }\end{array}$ & $\begin{array}{c}\text { IVDJ } 2101 \\
\text { Lampás efecto } \\
\text { de } 3 \text { tramas } \\
\text { lanzadas con } \\
\text { fondo de raso } \\
\text { de } 5 \text { escalonado } \\
3\end{array}$ & Fragmento de tejido & $\begin{array}{l}\text { IVDJ } 2103 \\
\text { Lam pás } \\
\text { efecto de } 2 \\
\text { tramas, } 1 \\
\text { lanzadas y } 1 \\
\text { espolinada. } \\
\text { Fondo raso de } \\
5 \text { escalonado } 3 .\end{array}$ \\
\hline $\begin{array}{c}\text { Fragmento de tejido del } \\
\text { s. XV-XVI. } \\
\text { Valenciano? }\end{array}$ & $\begin{array}{c}\text { IVDJ } 2111 \\
\text { Lampás efecto } \\
1 \text { trama } \\
\text { lanzada, } \\
\text { fondo tafetán } \\
\text { doble } \\
\text { Taqueté doble } \\
\text { cara }\end{array}$ & $\begin{array}{l}\text { Pragmento de tejido } \\
\text { del s. XIV-XV. } \\
\text { Andalusí }\end{array}$ & $\begin{array}{c}\text { IVDJ } 2120 \\
\text { Lampás efecto } \\
1 \text { trama } \\
\text { espolinada } \\
\text { (hilos dobles de } \\
\text { diferente } \\
\text { composición). } \\
\text { Fondo raso de } \\
5 \text { escalonado } 2 \\
\end{array}$ & $\begin{array}{c}\text { Fragmento de tejido } \\
\text { del s. XIV-XV. } \\
\text { Turco }\end{array}$ & $\begin{array}{l}\text { IVDJ } 2122 \\
\text { Lampás efecto } \\
2 \text { tramas, } \\
\text { fondo raso de } \\
5 \text { escalonado } 2 \\
\text { Taqueté efecto } \\
\text { de dos tramas }\end{array}$ \\
\hline${ }^{1}$ Análisis técnico efec & 等 & epresa & & & \\
\hline
\end{tabular}




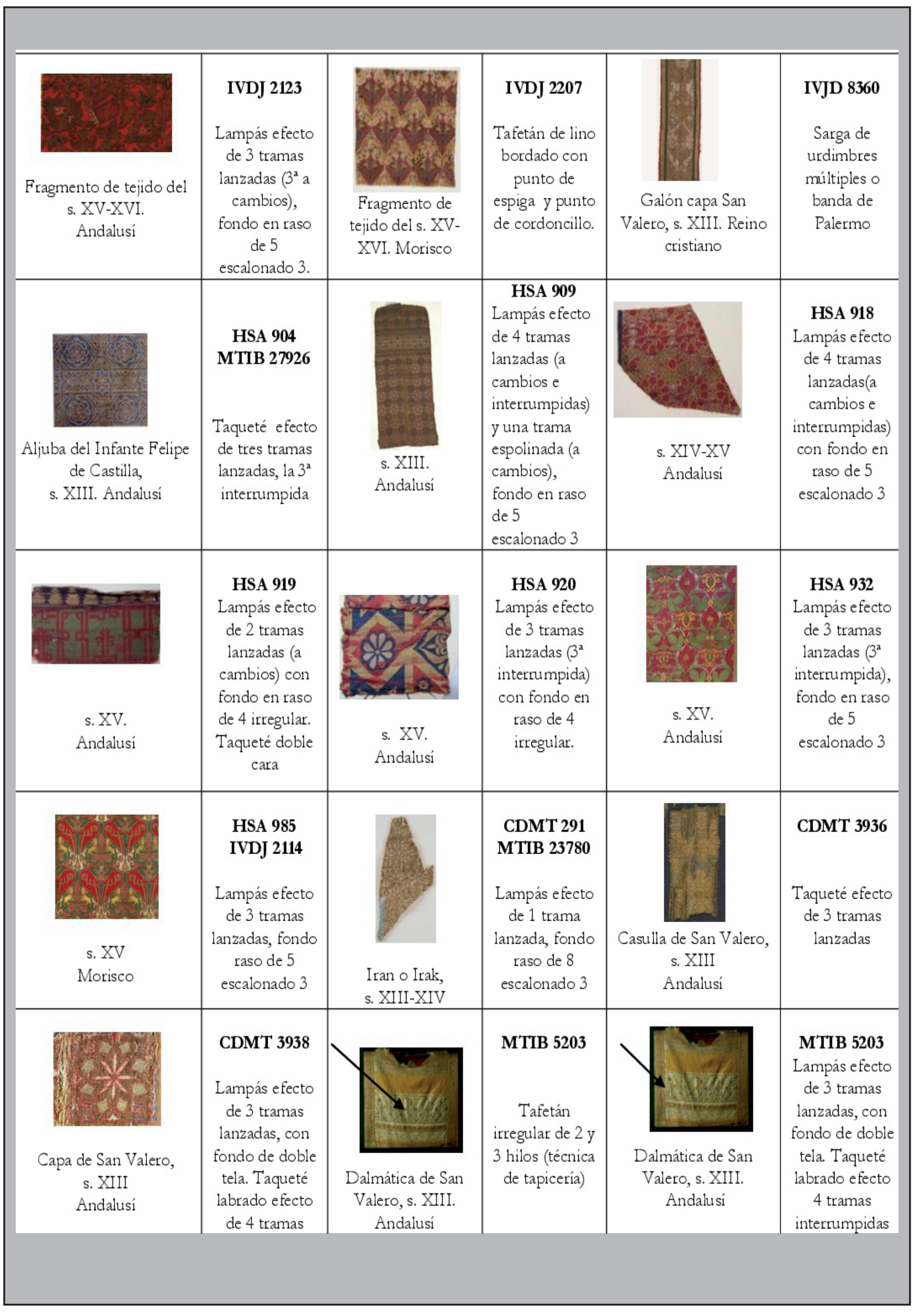




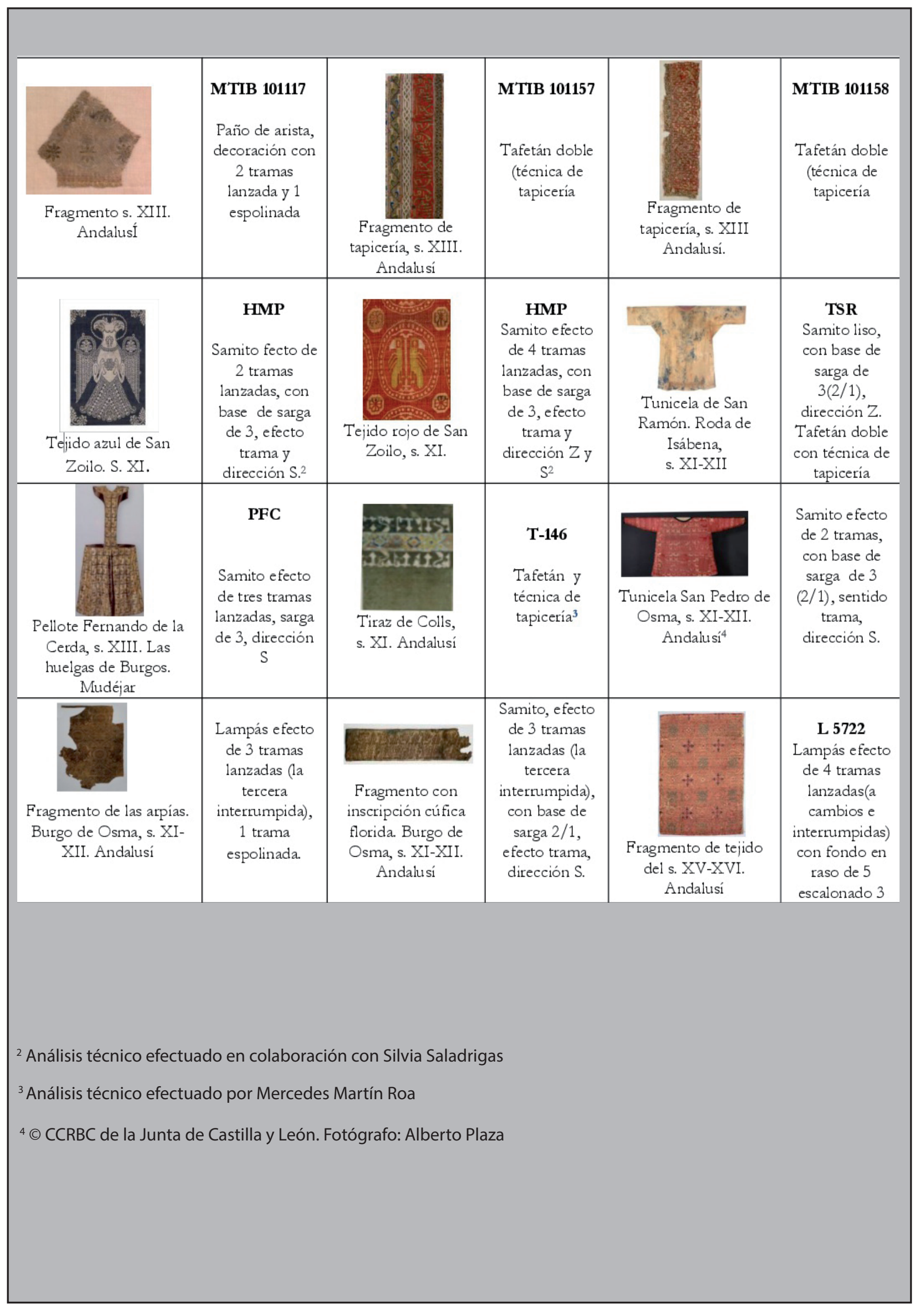


TABLA 2: RESULTADO DEL ANÁLISIS DE COLORANTES

\begin{tabular}{|c|c|c|}
\hline $\begin{array}{l}\text { N}^{\circ} \text { INV. } \\
\text { MUSEO }\end{array}$ & $\begin{array}{l}\text { TIPO DE HILO/ } \\
\text { COLOR }\end{array}$ & COLORANTE IDENTIFICADO (orden de abundancia) \\
\hline \multirow{4}{*}{ ASECT 6.1c } & Trama/Am arillo & $\begin{array}{c}\text { Tinte amarillo "K-glu” + Gualda? (Reseda luteola L.) + Fustete? (Cotinus coggygria } \\
\text { Scop) + Madera de Palo brasil (Caesalpinia spp.) }\end{array}$ \\
\hline & Trama/Azul oscuro & Índigo (Indigofera spp. ○ Isatis tinctoria L.) + Madera de Palo brasil (Caesalpinia spp.) \\
\hline & Trama/roja & Granza (Rubia tinctorum L.) + Madera de Palo brasil (Caesalpinia spp.) \\
\hline & Trama/Azul claro & Índigo (Indigofera spp. ○ Isatis tinctoria L.) \\
\hline \multirow{2}{*}{ ASECT 7.2} & Trama/Azul & Índigo (Indigofera spp. ○ Isatis tinctoria L.) + Madera de Palo brasil (Caesalpinia spp.) \\
\hline & Hilo costura/Azul & Índigo (Indigofera spp. ○ Isatis tinctoria L.) \\
\hline \multirow{4}{*}{ ASEC'T 7.3} & Urdimbre/rojo & $\begin{array}{l}\text { Quermes (Kermes vermilio Planchon) + Liquen de Orchilla (Roccella spp.) + Índigo } \\
\text { (Indigofera spp. o Isatis tinctoria L.) + Granza (especie no identificada) + Taninos }\end{array}$ \\
\hline & Hilo costura/ Azul & Índigo (Indigofera spp. ○ Isatis tinctoria L.) \\
\hline & $\begin{array}{c}\text { Cordón bolsa/ } \\
\text { Verde }\end{array}$ & $\begin{array}{c}\text { Gualda (Reseda luteola L.) +Índigo (Indigofera spp. o Isatis tinctoria L.) + Tinte no } \\
\text { identificado }\end{array}$ \\
\hline & $\begin{array}{l}\text { Cordón bolsa/ } \\
\text { Am arillo }\end{array}$ & Azafrán (Crocus sativus L.) \\
\hline \multirow[b]{3}{*}{ ASEC'T 7.3b } & $\begin{array}{c}\text { Trama/ } \\
\text { Rojo }\end{array}$ & Liquen de Orchilla (Roccella spp.) + Índigo (Indigofera spp. ○ Isatis tinctoria L.) \\
\hline & $\begin{array}{l}\text { Urdimbre } \\
\text { Azul }\end{array}$ & Índigo (Indigofera spp. ○ Isatis tinctoria L.) + Liquen de Orchilla (Roccella spp.) \\
\hline & $\begin{array}{l}\text { Hilo de costura/ } \\
\text { Rojo }\end{array}$ & $\begin{array}{c}\text { Quermes (Kermes vermilio Planchon) + Cochinilla polaca (Porpbyrophora polonica L.) } \\
\text { Cochinilla de Armenia (Porpbyrophora baemelii Brandt) o Cochinilla americana } \\
\text { (Dactylopius coccus Costa) }\end{array}$ \\
\hline ASECT 7.3d & $\begin{array}{c}\text { Trama/ } \\
\text { Crudo amarillento }\end{array}$ & Madera de Palo brasil (Caesalpinia spp.) \\
\hline \multirow{2}{*}{ ASECT $7.3 c$} & $\begin{array}{l}\text { Trama/ } \\
\text { Rojo }\end{array}$ & Laca (Kerria lacca Kerr) \\
\hline & $\begin{array}{l}\text { Trama/ } \\
\text { Verde }\end{array}$ & Índigo (Indigofera spp. ○ Isatis tinctoria L.) + Bayas Persas (Rhamnus spp.) \\
\hline ASECT7.3f & $\begin{array}{c}\text { Trama/ } \\
\text { Pardo verdoso }\end{array}$ & Índigo (Indigofera spp. ○ Isatis tinctoria L.) + Tinte amarillo " $K$-glu" + Taninos \\
\hline ASECT7.3e & $\begin{array}{c}\text { Trama/ } \\
\text { Rojo }\end{array}$ & Quermes (Kermes vermilio Planchon) + Índigo (Indigofera spp. ○ Isatis tinctoria L.) \\
\hline \multirow{2}{*}{ IVDJ 2061} & $\begin{array}{c}\text { Trama/ } \\
\text { Rojo }\end{array}$ & Granza (Rubia tinctorum L.) + Madera de Palo brasil (Caesalpinia spp.) + Taninos? \\
\hline & $\begin{array}{l}\text { Trama/ } \\
\text { Amarillo }\end{array}$ & Tinte amarillo "K-gll" + Taninos? \\
\hline \multirow[b]{2}{*}{ IVDJ 2061} & $\begin{array}{c}\text { Trama/ } \\
\text { Azul }\end{array}$ & Indigo (Indigofera spp. ○ Isatis tinctoria L.) \\
\hline & $\begin{array}{l}\text { Alma hilo } \\
\text { entorchado/ } \\
\text { Am arillento }\end{array}$ & Tinte amarillo no identificado designado como: "Tinte amarillo rutind" + Taninos? \\
\hline \multirow{4}{*}{ IVDJ 2070} & $\begin{array}{l}\text { Trama/ } \\
\text { Amarillo }\end{array}$ & Gualda (Reseda luteola L.) \\
\hline & $\begin{array}{c}\text { Trama/ } \\
\text { Verde }\end{array}$ & Gualda (Reseda luteola L.) + Indigo (Indigofera spp. ○ Isatis tinctoria L.) \\
\hline & $\begin{array}{c}\text { Trama/ } \\
\text { Rojo }\end{array}$ & Quermes (Kermes vermilio Planchon) \\
\hline & $\begin{array}{l}\text { Trama/ } \\
\text { Azul }\end{array}$ & Índigo (Indigofera spp. ○ Isatis tinctoria L.) \\
\hline
\end{tabular}




\begin{tabular}{|c|c|c|}
\hline IVDJ 2086 & $\begin{array}{c}\text { Trama/ } \\
\text { Roja }\end{array}$ & Quermes (Kermes vermilio Planchon) + Granza (especie no identificada) \\
\hline IVDJ 2057 & $\begin{array}{l}\text { Trama/ } \\
\text { Verde }\end{array}$ & Indigo (Indigofera spp. ○ Isatis tinctoria L.) + Gualda (Reseda luteola L.) \\
\hline \multirow{3}{*}{ IVDJ 2075} & $\begin{array}{c}\text { Trama } \\
\text { Am arillo/ } \\
\text { banda tricolor }\end{array}$ & Genista o aliaga (Genista spp.) + Gualda (Reseda luteola L.) \\
\hline & $\begin{array}{l}\text { Trama/ } \\
\text { Rojo }\end{array}$ & Granza (Rubia tinctorum L.) \\
\hline & $\begin{array}{l}\text { Trama } \\
\text { Pardo rosado/ } \\
\text { banda tricolor }\end{array}$ & Fustete (Cotinus coggygria Scop.) + Madera de Palo brasil (Caesalpinia spp.) \\
\hline \multirow{6}{*}{ IVDJ-2076 } & $\begin{array}{l}\text { Urdimbre/ } \\
\text { Azul grisáceo }\end{array}$ & Indigo (Indigofera spp. ○ Isatis tinctoria L.) \\
\hline & $\begin{array}{l}\text { Urdimbre/ } \\
\text { Rojo }\end{array}$ & Granza (Rubia tinctorum L.) \\
\hline & $\begin{array}{c}\text { Trama/ } \\
\text { Rojo anaranjado }\end{array}$ & Granza (Rubia tinctorum L.) \\
\hline & $\begin{array}{l}\text { Trama/ } \\
\text { Verde }\end{array}$ & $\begin{array}{c}\text { Gualda (Reseda luteola L.) + Indigo (Indigofera spp. ○ Isatis tinctoria L.) }+ \text { ¿Tinte } \\
\text { amarillo tipo carotenoide? }\end{array}$ \\
\hline & $\begin{array}{l}\text { Trama/ } \\
\text { Pardo }\end{array}$ & $\begin{array}{c}\text { Madera de Palo brasil (Caesalpinia spp.) + Indigo (Indigofera spp. } \circ \text { Isatis tinctoria L.) } \\
\text { + Taninos hidrolizables }\end{array}$ \\
\hline & $\begin{array}{l}\text { Trama/ } \\
\text { Amarillo }\end{array}$ & Fustete (Cotinus coggygria Scop.) \\
\hline \multirow{3}{*}{ IVDJ 2082} & $\begin{array}{l}\text { Trama/ } \\
\text { Rojo }\end{array}$ & $\begin{array}{c}\text { Madera de Palo brasil (Caesalpinia spp.) + Quermes (Kermes vermilio Planchon) + } \\
\text { Granza (Rubia tinctorum L.) }\end{array}$ \\
\hline & $\begin{array}{c}\text { Trama/ } \\
\text { Rosa }\end{array}$ & Cártamo o Alazor (Carthamus tinctorius L.) \\
\hline & $\begin{array}{l}\text { Alma entorchado/ } \\
\text { Rosa }\end{array}$ & Cártamo o Alazor (Cartbamus tinctorius L.) + ¿Tinte rojo desconocido? \\
\hline \multirow{7}{*}{ IVDJ 2103} & $\begin{array}{l}\text { Urdimbre de base/ } \\
\text { Azul }\end{array}$ & Indigo (Indigofera spp. ○ Isatis tinctoria L.) \\
\hline & $\begin{array}{l}\text { Urdimbre de base/ } \\
\text { Rojo }\end{array}$ & Granza (probablemente Rubia peregrina L.) + Liquen de Orchilla (Roccella spp.) \\
\hline & $\begin{array}{l}\text { Urdimbre de base/ } \\
\text { Negro }\end{array}$ & $\begin{array}{l}\text { Granza (probablemente Rubia peregrina L.) + Taninos + Gualda (Reseda luteola L.) + } \\
\text { Indigo (Indigofera spp. ○ Isatis tinctoria L.) + Madera de Palo brasil (Caesalpinia spp.) } \\
\quad+\text { Quermes (Kermes vermilio Planchon) + Liquen de Orchilla (Roccella spp.) }\end{array}$ \\
\hline & $\begin{array}{l}\text { Urdim bre de base/ } \\
\text { Am arillo }\end{array}$ & Gualda (Reseda luteola L.) + trazas de Fustete (Cotinus coggygria Scop) \\
\hline & $\begin{array}{c}\text { Trama/ } \\
\text { Verde }\end{array}$ & Gualda (Reseda luteola L.) + Indigo (Indigofera spp. ○ Isatis tinctoria L.) \\
\hline & $\begin{array}{l}\text { Alma entorchado/ } \\
\text { Amarillo }\end{array}$ & $\begin{array}{l}\text { Gualda (Reseda luteola L.) + Taninos (probable zumaque-Rhus coriaria L.) + } \\
\text { Madera de Palo brasil (Caesalpinia spp.) }\end{array}$ \\
\hline & $\begin{array}{c}\text { Trama/ } \\
\text { Rojo }\end{array}$ & Granza (probablemente Rubia peregrina L.) + Liquen de Orchilla (Roccella spp.) \\
\hline \multirow{5}{*}{ IVDJ 2114} & $\begin{array}{l}\text { Urdim bre de base/ } \\
\text { Rosa }\end{array}$ & Granza (probable Rubia tinctorum L.) \\
\hline & $\begin{array}{l}\text { Urdimbre de base/ } \\
\text { Verde }\end{array}$ & Gualda (Reseda luteola L.) + Indigo (Indigofera spp. ○ Isatis tinctoria L.) \\
\hline & $\begin{array}{l}\text { Trama/ } \\
\text { Rojo }\end{array}$ & Quermes (Kermes vermilio Planchon) + Taninos hidrolizables \\
\hline & $\begin{array}{l}\text { Trama/ } \\
\text { Am arillo }\end{array}$ & Gualda (Reseda luteola L.) \\
\hline & $\begin{array}{l}\text { Trama/ } \\
\text { Verde }\end{array}$ & Gualda (Reseda luteola L.) + Indigo (Indigofera spp. ○ Isatis tinctoria L.) \\
\hline
\end{tabular}




\begin{tabular}{|c|c|c|}
\hline & $\begin{array}{c}\text { Trama/ } \\
\text { Pardo }\end{array}$ & Madera de Palo brasil (Caesalpinia spp.) + Taninos \\
\hline \multirow{3}{*}{ IVDJ 8360} & $\begin{array}{c}\text { Trama/ } \\
\text { Rojo }\end{array}$ & Granza (Rubia tinctorum L.) + Madera de Palo brasil (Caesalpinia spp.) \\
\hline & $\begin{array}{c}\text { Alma del } \\
\text { entorchado/ } \\
\text { Amarillo } \\
\end{array}$ & Gualda (Reseda luteola L.) + trazas de Fustete (Cotinus coggygria Scop.) \\
\hline & $\begin{array}{c}\text { Trama/ } \\
\text { Verde }\end{array}$ & $\begin{array}{c}\text { Gualda (Reseda luteola L.) + Genista o aliaga (Genista spp.) + Indigo (Indigofera spp. } \circ \\
\text { Isatis tinctoria L.) }\end{array}$ \\
\hline \multirow{5}{*}{ IVDJ 2084} & $\begin{array}{l}\text { Urdimbre/ } \\
\text { Azul }\end{array}$ & $\begin{array}{l}\text { Indigo (Indigofera spp. } \circ \text { Isatis tinctoria L.) +Liquen de Orchilla (Roccella spp.) + trazas } \\
\text { de Granza }\end{array}$ \\
\hline & $\begin{array}{l}\text { Urdimbre/ } \\
\text { Amarillo }\end{array}$ & $\begin{array}{c}\text { Gualda (Reseda luteola L.)+ Fustete (Cotinus coggygria Scop.) + Madera de Palo brasil } \\
\text { (Caesalpinia spp.) }\end{array}$ \\
\hline & $\begin{array}{l}\text { Urdimbre/ } \\
\text { Rojo }\end{array}$ & Quermes (Kermes vermilio Planchon) + Granza (Rubia tinctorum L.) + Taninos \\
\hline & $\begin{array}{c}\text { Urdimbre / } \\
\text { verde }\end{array}$ & Gualda (Reseda luteola L.) + Indigo (Indigofera spp. ○ Isatis tinctoria L.) \\
\hline & $\begin{array}{c}\text { Trama/ } \\
\text { Rosa }\end{array}$ & Granza (Rubia tinctorum L.) + Quermes (Kermes vermilio Planchon) + Taninos \\
\hline \multirow{7}{*}{ IVDJ 2085} & $\begin{array}{l}\text { Urdimbre/ } \\
\text { Roja }\end{array}$ & Quermes (Kermes vermilio Planchon) + Taninos hidrolizables \\
\hline & $\begin{array}{c}\begin{array}{c}\text { Urdimbre/ } \\
\text { Verde }\end{array} \\
\end{array}$ & $\begin{array}{c}\text { Gualda (Reseda luteola L.)+ Indigo (Indigofera spp. o Isatis tinctoria L.) + Fustete } \\
\text { (Cotinus coggygria Scop.) + Madera de Palo brasil (Caesalpinia spp.) }\end{array}$ \\
\hline & $\begin{array}{c}\text { Trama/ } \\
\text { Amarillo dorado }\end{array}$ & $\begin{array}{c}\text { Gualda (Reseda luteola L.)+ Fustete (Cotinus coggygria Scop.) + Madera de Palo brasil } \\
\text { (Caesalpinia spp.) }\end{array}$ \\
\hline & $\begin{array}{l}\text { Trama/ } \\
\text { Rosado }\end{array}$ & $\begin{array}{c}\text { Granza (probablemente Rubia peregrina L.) + Madera de Palo brasil (Caesalpinia spp.) } \\
+ \text { Quermes (Kermes vermilio Planchon) }\end{array}$ \\
\hline & $\begin{array}{l}\text { Urdimbre/ } \\
\text { Azul }\end{array}$ & $\begin{array}{c}\text { Indigo (Indigofera spp. ○ Isatis tinctoria L.) + Granza (probablemente Rubia peregrina } \\
\text { L.) + Liquen de Orchilla (Roccella spp.) }\end{array}$ \\
\hline & $\begin{array}{c}\text { Trama/ } \\
\text { Rojo }\end{array}$ & Granza (especie desconocida) \\
\hline & $\begin{array}{l}\text { Urdimbre/ } \\
\text { Amarillo anaranjado }\end{array}$ & $\begin{array}{c}\text { Fustete (Cotinus coggygria Scop.) }+ \text { Madera de Palo brasil (Caesalpinia spp.) }+ \\
\text { probablemente Gualda (Reseda luteola L.) }\end{array}$ \\
\hline IVDJ 2111 & $\begin{array}{l}\text { Urdimbre/ } \\
\text { Roja }\end{array}$ & Cochinilla \\
\hline \multirow{4}{*}{ IVDJ 2120} & $\begin{array}{l}\text { Trama/ } \\
\text { Amarilla }\end{array}$ & $\begin{array}{c}\text { Colorante amarillo no identificado cuyos componentes principales son flavonoles } \\
+ \text { Fustete (Cotinus coggygria Scop.) }\end{array}$ \\
\hline & $\begin{array}{c}\text { Trama/ } \\
\text { Roja }\end{array}$ & $\begin{array}{l}\text { Quermes (Kermes vermilio Planchon) + Taninos hidrolizables + Granza (especie } \\
\text { desconocida) }\end{array}$ \\
\hline & $\begin{array}{l}\text { Urdimbre/ } \\
\text { Roja }\end{array}$ & $\begin{array}{l}\text { Quermes (Kermes vermilio Planchon) + Taninos hidrolizables + Granza (especie } \\
\text { desconocida) (menos cantidad) }\end{array}$ \\
\hline & $\begin{array}{l}\text { Urdimbre/ } \\
\text { Azul }\end{array}$ & Indigo (Indigofera spp. ○ Isatis tinctoria L.) \\
\hline \multirow{7}{*}{ IVDJ 2122} & $\begin{array}{l}\text { Urdimbre/ } \\
\text { Rojo }\end{array}$ & Laca (Kerria lacca Kerr) + Granza (probable Rubia tinctorum L.) \\
\hline & $\begin{array}{c}\text { Trama/ } \\
\text { Rojo }\end{array}$ & Laca (Kerria lacca Kerr) + Granza (probable Rubia tinctorum L.) \\
\hline & $\begin{array}{l}\text { Trama/ } \\
\text { Naranja }\end{array}$ & Granza (probable Rubia tinctorum L.) \\
\hline & $\begin{array}{l}\text { Trama/ } \\
\text { Negro }\end{array}$ & $\begin{array}{c}\text { Indigo (Indigofera spp. } \circ \text { Isatis tinctoria L.) + Granza + Tinte amarillo tipo Gualda + } \\
\text { Taninos }\end{array}$ \\
\hline & $\begin{array}{l}\text { Alm a entorchado/ } \\
\text { Am arillo }\end{array}$ & $\begin{array}{c}\text { Gualda (Reseda luteola L.) + trazas de Fustete (Cotinus coggygria Scop.) } \\
\text { Madera de Palo brasil (Caesalpinia spp.) }\end{array}$ \\
\hline & $\begin{array}{c}\text { Trama/ } \\
\text { Azul }\end{array}$ & Indigo (Indigofera spp. $\circ$ Isatis tinctoria L.) \\
\hline & $\begin{array}{l}\text { Trama/ } \\
\text { Verde }\end{array}$ & Gualda (Reseda luteola L.) + Indigo (Indigofera spp. ○ Isatis tinctoria L.) \\
\hline
\end{tabular}




\begin{tabular}{|c|c|c|}
\hline \multirow{5}{*}{ IVDJ 2207} & $\begin{array}{l}\text { Hilo del bordado/ } \\
\text { Rojo }\end{array}$ & Quermes (Kermes vermilio Planchon) + Taninos hidrolizables \\
\hline & $\begin{array}{l}\text { Hilo del bordado/ } \\
\text { Azul }\end{array}$ & Indigo (Indigofera spp. ○ Isatis tinctoria L.) \\
\hline & $\begin{array}{l}\text { Hilo del bordado/ } \\
\text { Verde }\end{array}$ & Gualda (Reseda luteola L.) + Indigo (Indigofera spp. ○ Isatis tinctoria L.) \\
\hline & $\begin{array}{l}\text { Hilo del bordado/ } \\
\text { Marrón }\end{array}$ & Taninos \\
\hline & $\begin{array}{l}\text { Hilo del bordado/ } \\
\text { Am arillo }\end{array}$ & Gualda (Reseda luteola L.) \\
\hline \multirow{4}{*}{ HSA 918} & $\begin{array}{c}\text { Trama/ } \\
\text { roja }\end{array}$ & $\begin{array}{l}\text { Quermes (Kermes vermilio Planchon) + Taninos hidrolizables + Granza } \\
\text { (probablemente Rubia peregrina L.) }\end{array}$ \\
\hline & $\begin{array}{l}\text { Urdimbre/ } \\
\text { Rojo }\end{array}$ & Granza (probablemente Rubia peregrina L.) + Quermes (Kermes vermilio Planchon) \\
\hline & $\begin{array}{c}\text { Trama/ } \\
\text { Amarilla } \\
\end{array}$ & Gualda (Reseda luteola L.) \\
\hline & $\begin{array}{c}\text { Trama/ } \\
\text { verde }\end{array}$ & Gualda (Reseda luteola L.) + Indigo (Indigofera spp. ○ Isatis tinctoria L.) \\
\hline \multirow{5}{*}{ HSA 920} & $\begin{array}{l}\text { Urdimbre/ } \\
\text { Rojo rosado }\end{array}$ & Quermes (Kermes vermilio Planchon) + Taninos hidrolizables \\
\hline & $\begin{array}{l}\text { Urdimbre/ } \\
\text { Rojo }\end{array}$ & Granza (Rubia tinctorum L.) \\
\hline & $\begin{array}{c}\text { Trama/ } \\
\text { Azul }\end{array}$ & Indigo (Indigofera spp. ○ Isatis tinctoria L.) \\
\hline & $\begin{array}{c}\text { Trama/ } \\
\text { Roja }\end{array}$ & Granza (Rubia tinctorum L.) \\
\hline & $\begin{array}{l}\text { Trama/ } \\
\text { Amarilla }\end{array}$ & Gualda (Reseda luteola L.) \\
\hline \multirow[b]{4}{*}{ HSA 932} & $\begin{array}{c}\text { Trama/ } \\
\text { Verde }\end{array}$ & Indigo (Indigofera spp. ○ Isatis tinctoria L.) + Gualda (Reseda luteola L.) \\
\hline & $\begin{array}{l}\text { Trama/ } \\
\text { Amarillo }\end{array}$ & $\begin{array}{c}\text { Gualda (Reseda luteola L.) + trazas de Fustete (Cotinus coggygria Scop.) trazas de } \\
\text { Madera de Palo brasil (Caesalpinia spp.) }\end{array}$ \\
\hline & $\begin{array}{l}\text { Trama/ } \\
\text { Rojo }\end{array}$ & $\begin{array}{c}\text { Quermes (Kermes vermilio Planchon) + Taninos hidrolizables + Granza (Rubia } \\
\text { tinctorum L.) }\end{array}$ \\
\hline & $\begin{array}{l}\text { Trama/ } \\
\text { Púrpura }\end{array}$ & $\begin{array}{c}\text { Quermes (Kermes vermilio Planchon) + Granza (probablemente Rubia tinctorum L.) + } \\
\text { Liquen de Orchilla (Roccella spp.) }\end{array}$ \\
\hline \multirow[b]{3}{*}{ HSA985 } & $\begin{array}{c}\text { Urdimbre/ } \\
\text { Verde }\end{array}$ & $($ Indigofera spp. $\circ$ Isatis tinctoria L.) + Gualda (Reseda luteola L.) \\
\hline & $\begin{array}{l}\text { Trama/ } \\
\text { Verde }\end{array}$ & Gualda (Reseda luteola L.) + Indigo (Indigofera spp. ○ Isatis tinctoria L.) \\
\hline & $\begin{array}{l}\text { Trama/ } \\
\text { Rojo }\end{array}$ & Quermes (Kermes vermilio Planchon) + Taninos hidrolizables + Trazas de Granza \\
\hline HSA 904 & $\begin{array}{l}\text { Alm a entorchado/ } \\
\text { Am arillo claro }\end{array}$ & Taninos hidrolizables + trazas de Fustete (Cotinus coggygria Scop.) \\
\hline \multirow{2}{*}{$\begin{array}{l}\text { HMP } \\
\text { Tejido azul }\end{array}$} & $\begin{array}{l}\text { Trama/Rojo (cenefa } \\
\text { banda superior) }\end{array}$ & Quermes (Kermes vermilio Planchon) \\
\hline & $\begin{array}{l}\text { Trama/Rojo (banda } \\
\text { de inscripción) }\end{array}$ & Granza \\
\hline \multirow{3}{*}{$\begin{array}{l}\text { HMP } \\
\text { Tejido rojo }\end{array}$} & Trama/ Rojo & Granza \\
\hline & $\begin{array}{l}\text { Trama/ Am arillo } \\
\text { verdoso }\end{array}$ & $\begin{array}{c}\text { Gualda(Reseda luteola L. })+ \text { Indigo (Indigofera spp. ○ Isatis tinctoria L. })+ \text { granza (Rubia } \\
\text { tinctoria L.). }\end{array}$ \\
\hline & Trama/ Púrpura & Liquen de Orchilla (Roccella spp.)? \\
\hline IVDJ 2082 & Cuero dorado & $\begin{array}{l}\text { Taninos hidrolizables y flavonoides atribuidos a proceso de curtido con zumaque } \\
\text { (Rhus coriaria L.) + Posible presencia de gualda (Reseda luteola L.). }\end{array}$ \\
\hline IVDJ 2103 & Cuero dorado & $\begin{array}{c}\text { Taninos hidrolizables y flavonoides atribuidos al proceso de curtido con zumaque } \\
\qquad \begin{array}{c}\text { (Rbus coriaria L.) }+ \text { Gualda (Reseda luteola L.) }+ \text { Antraquinonas de procedencia } \\
\text { incierta. }\end{array}\end{array}$ \\
\hline
\end{tabular}




\begin{tabular}{|c|c|l|}
\hline $\begin{array}{c}\text { Tunicela de San } \\
\text { Ramón }\end{array}$ & Cuero dorado & Taninos hidrolizables de procedencia incierta. \\
\hline IVDDJ 2071 & Cuero dorado & $\begin{array}{l}\text { Taninos hidrolizables y flavonoides atribuidos al proceso de curtido con zumaque } \\
\text { Rhus coriaria L.) + posible presencia de gualda (Reseda luteola L.) }+ \text { abundancia de } \\
\text { compuestos desconocidos probablemente procedentes de otra especie vegetal. }\end{array}$ \\
\hline ASECT 6.1c & Cuero dorado & $\begin{array}{l}\text { Taninos }+ \text { Gualda (Reseda luteola L.) + trazas de Cochinilla e Indigo (Indigofera spp. o } \\
\text { Isatis tinctoria L.) }\end{array}$ \\
\hline $\begin{array}{c}\text { Pellote Fernando } \\
\text { de La Cerda }\end{array}$ & $\begin{array}{c}\text { Intestino con plata } \\
\text { dorada }\end{array}$ & Ácidos grasos de procedencia incierta (grasa animal o aceite vegetal). \\
\hline IVDJ 2083 & $\begin{array}{c}\text { Intestino con plata } \\
\text { dorada }\end{array}$ & Ácidos grasos de procedencia incierta (grasa animal o aceite vegetal). \\
\hline
\end{tabular}

TABLA 3: RESULTADO DE ANÁLISIS DE HILOS METÁLICOS

\begin{tabular}{|c|c|c|c|c|c|c|}
\hline CLAVE MUESTRAS & $\begin{array}{c}\text { TIPO DE } \\
\text { ENTORCHADO }\end{array}$ & \multirow{2}{*}{\multicolumn{3}{|c|}{ METAL IDENTIFICADO en $\%$}} & \multicolumn{2}{|c|}{ MEDIDA EN $\mu$} \\
\hline Tela de Colls & PIEL & & & & Ancho & Grosor \\
\hline T-146 (estratig) & $\mathrm{X} 4$ & $\begin{array}{c}\mathbf{A u} \\
91.35\end{array}$ & & $\begin{array}{c}\mathbf{A g} \\
8.64\end{array}$ & & $\begin{array}{l}10 \mu \\
1.5 \mu\end{array}$ \\
\hline ASC'T & PIEL & \multicolumn{3}{|c|}{ Oro con plata } & Ancho & Grosor \\
\hline ASECT-6.1c-metal & $\mathrm{X} 1$ Area & \multicolumn{2}{|l|}{$\begin{array}{c}\text { Au } \\
80.23\end{array}$} & $\begin{array}{c}\mathbf{A g} \\
19.92\end{array}$ & ---- & $23.5 \mu$ \\
\hline ASECT-7.4b-metal & $\mathrm{X} 1$ Area & \multicolumn{2}{|l|}{$\begin{array}{c}\text { Au } \\
88.64\end{array}$} & $\begin{array}{c}\mathbf{A g} \\
11.36\end{array}$ & $\begin{array}{c}---- \\
-\cdots\end{array}$ & $41 \mu$ \\
\hline ASECT-9-metal & X1 Area & \multicolumn{2}{|l|}{$\begin{array}{c}\text { Au } \\
82.05\end{array}$} & $\begin{array}{c}\mathbf{A g} \\
16.88\end{array}$ & ---- & $56.5 \mu$ \\
\hline ASECT9A & $\mathrm{x} 2$ & \multicolumn{2}{|l|}{$\begin{array}{c}\text { Au } \\
83.54\end{array}$} & $\begin{array}{c}\mathbf{A g} \\
16.48\end{array}$ & $350 \mu$ & $32.5 \mu$ \\
\hline ASECT9B & X3 Area & \multicolumn{2}{|l|}{$\begin{array}{c}\text { Au } \\
78.10\end{array}$} & $\begin{array}{c}\mathbf{A g} \\
21.90\end{array}$ & $375 \mu$ & \\
\hline ASECT9C & General X2 & $\begin{array}{c}\text { Au } \\
82.60 \\
\end{array}$ & $\underset{16.15}{\mathbf{A g}}$ & $\begin{array}{c}\mathbf{C u} \\
1.24 \\
\end{array}$ & $350 \mu$ & \\
\hline ASECT9D & Media puntual & $\begin{array}{c}\mathbf{A u} \\
81.21 \\
\end{array}$ & $\begin{array}{c}\mathbf{A g} \\
17.96\end{array}$ & $\begin{array}{c}\mathbf{C u} \\
0.83 \\
\end{array}$ & $475 \mu$ & $33 \mu$ \\
\hline ASECT9E & X7 Area & $\begin{array}{c}\text { Au } \\
75.23\end{array}$ & $\begin{array}{c}\mathbf{A g} \\
23.64\end{array}$ & $\begin{array}{c}\mathbf{C u} \\
1.13\end{array}$ & $675 \mu$ & $36 \mu$ \\
\hline IVDJ & Lámina m etálica & \multicolumn{3}{|c|}{ Plata dorada } & Ancho & Grosor \\
\hline IVDJ 2076 & $\begin{array}{l}\text { Anv X1 } \\
\text { RevX3 }\end{array}$ & $\begin{array}{c}\text { Au } \\
28.57 \\
0.0\end{array}$ & $\begin{array}{c}\mathbf{A g} \\
66.92 \\
89.52\end{array}$ & $\begin{array}{c}\mathbf{C u} \\
4.49 \\
9.93\end{array}$ & $183 \mu$ & $11.3 \mu$ \\
\hline IVDJ 2122 & plata & $\begin{array}{c}\mathbf{A u} \\
3.22\end{array}$ & $\begin{array}{c}\mathbf{A g} \\
89.70\end{array}$ & $\begin{array}{c}\mathbf{C u} \\
0.50\end{array}$ & $215 \mu$ & $14.3 \mu$ \\
\hline IVDJ 8360 & $\begin{array}{l}\text { Anv X4 } \\
\text { Rev X5 }\end{array}$ & $\begin{array}{c}\text { Au } \\
9.82 \\
0.0\end{array}$ & $\begin{array}{c}\mathbf{A g} \\
71.80 \\
92.22\end{array}$ & $\begin{array}{c}\mathbf{C u} \\
6.76 \\
0.5\end{array}$ & $281 \mu$ & $19.4 \mu$ \\
\hline IVDJ & PIEL & \multicolumn{3}{|c|}{ Oro con plata } & Ancho & Grosor \\
\hline IVDJ 2103 & X2 (plata dorada) & $\begin{array}{c}\mathbf{A u} \\
13.57\end{array}$ & & $\begin{array}{c}\mathbf{A g} \\
74.48\end{array}$ & $331 \mu$ & $45 \mu$ \\
\hline IVDJ 2082 & $\mathrm{x} 1$ & $\begin{array}{c}\text { Au } \\
92.16\end{array}$ & & $\begin{array}{c}\mathbf{A g} \\
7.84\end{array}$ & $377 \mu$ & $31.3 \mu$ \\
\hline
\end{tabular}




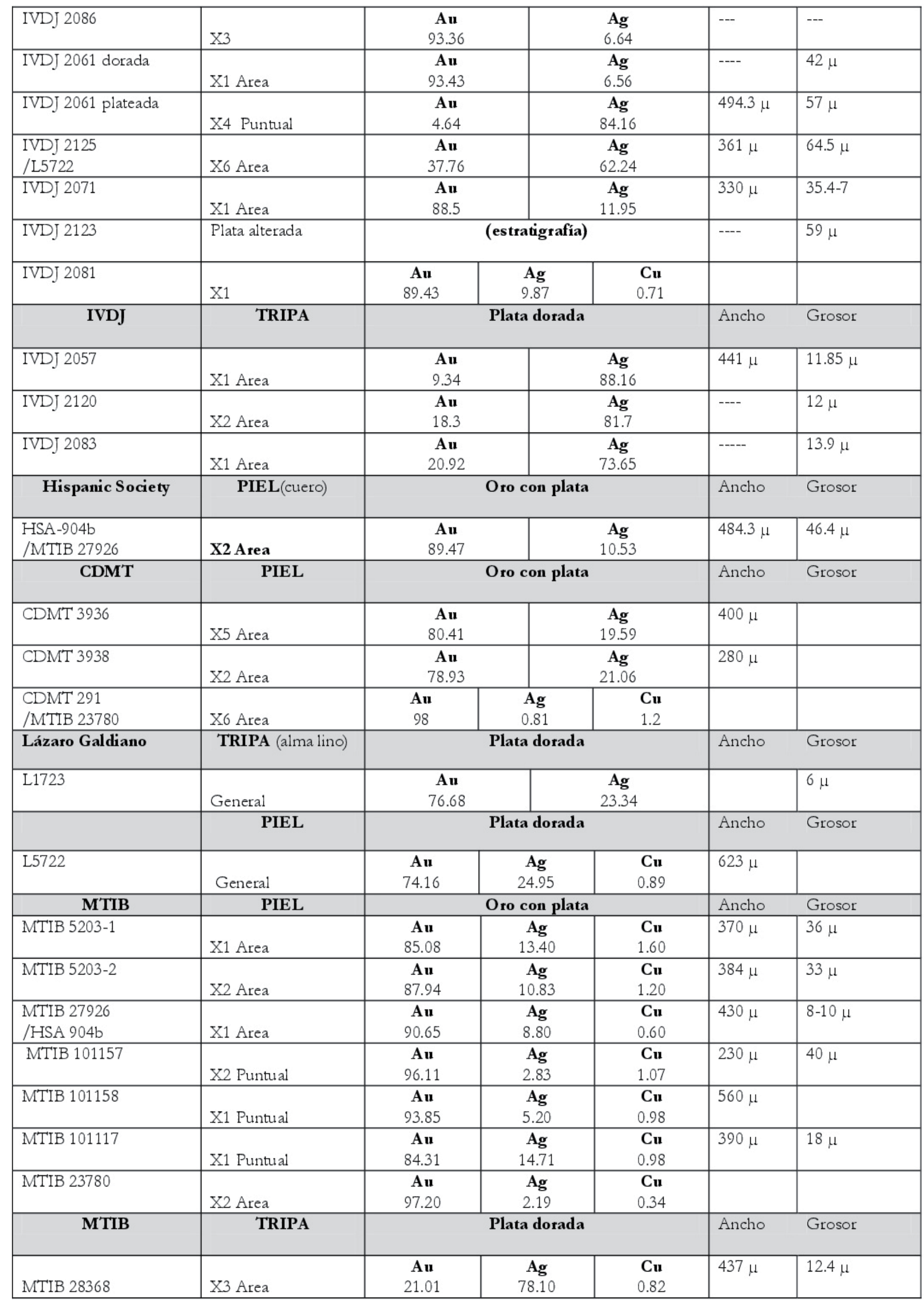




\begin{tabular}{|c|c|c|c|c|c|c|}
\hline MTIB 101117 & X1 Puntual & $\begin{array}{c}\text { Au } \\
84.31\end{array}$ & $\begin{array}{c}\mathbf{A g} \\
14.71 \\
\end{array}$ & $\begin{array}{c}\mathbf{C u} \\
0.98\end{array}$ & $390 \mu$ & $18 \mu$ \\
\hline $\begin{array}{l}\text { Tunicela de San } \\
\text { Ramón }\end{array}$ & PIEL (cuero) & \multicolumn{3}{|c|}{ Oro con plata } & Ancho & Grosor \\
\hline TSR & X2 Area & $\begin{array}{c}\text { Au } \\
91.80\end{array}$ & & $\begin{array}{c}\text { Ag } \\
8.20\end{array}$ & $217 \mu$ & $19.5 \mu$ \\
\hline $\begin{array}{c}\text { Pellote Fernando de } \\
\text { la Cerda }\end{array}$ & TRIPA & \multicolumn{3}{|c|}{ Plata dorada } & Ancho & Grosor \\
\hline $\mathrm{PFC}$ & X6 Area & $\begin{array}{c}\text { Au } \\
83.40\end{array}$ & & $\begin{array}{c}\mathbf{A g} \\
16.59 \\
\end{array}$ & $360 \mu$ & $10.5 \mu$ \\
\hline
\end{tabular}

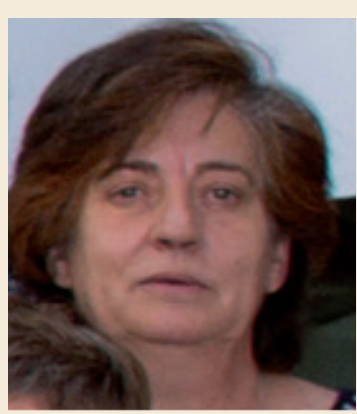

\section{Pilar Borrego Díaz}

pilar.borrego@mecd.es

Área de Investigación y Formación. Instituto de Patrimonio Cultural de España (IPCE)

Licenciada en Ciencias Químicas, supervisora de instalaciones radiactivas, máster en Patrimonio Cultural y restauradora del departamento de tejidos del IPCE desde 1986, donde conjuga la labor de conservación y restauración con la ejecución y dirección de proyectos.

Desde 2011 pasa a formar parte del Área de Investigación y Formación, donde realiza el análisis técnico de tejidos, caracterización de fibras y supervisión de la instalación de rayos $\mathrm{X}$ del departamento de estudios físicos. Es autora de numerosas publicaciones nacionales e internacionales. 

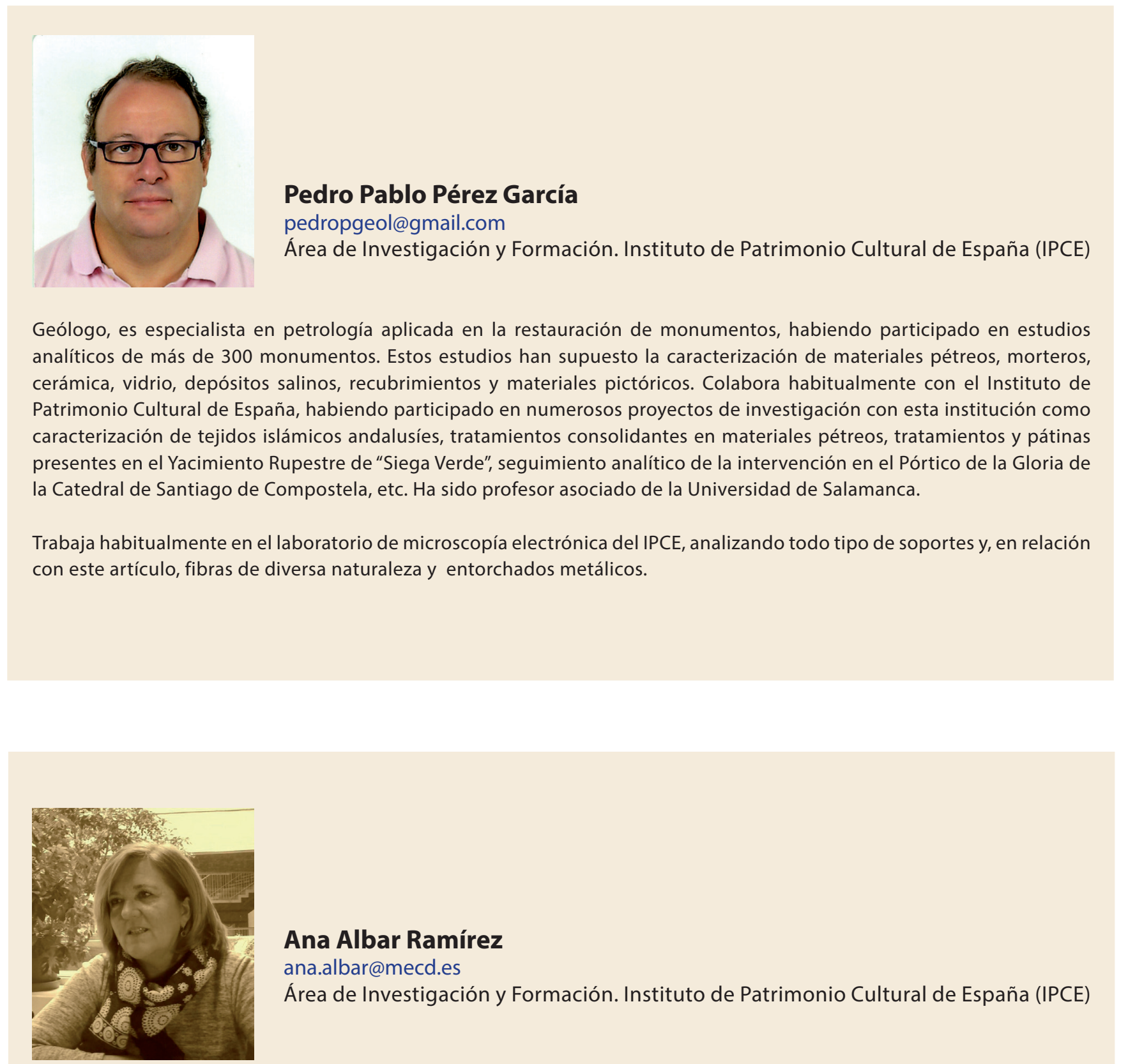

\section{Ana Albar Ramírez}

ana.albar@mecd.es

Área de Investigación y Formación. Instituto de Patrimonio Cultural de España (IPCE)

Técnico superior de análisis y control de la rama química. Ha desarrollado su carrera profesional como personal laboral en el Laboratorio de Control de Dopaje del CSD (Consejo Superior de Deportes) y desde el 2008 en el laboratorio de análisis de materiales del IPCE. Actualmente se ocupa de la coordinación de la Base de Datos de las muestras analizadas en el laboratorio y del análisis de las muestras mediante Microscopía electrónica, principalmente de policromías y tejidos. 


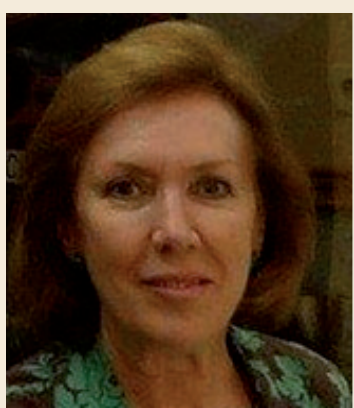

\section{Cristina Partearroyo}

partearroyo.c@gmail.com

Instituto de Valencia de Don Juan. Madrid

Historiadora del Arte por la Universidad Complutense de Madrid. Conservadora del museo del Instituto de Valencia de Don Juan (Madrid). Investigadora de Artes Aplicadas, especialmente textiles andalusíes y alfombras españolas y orientales, cuyo resultado se plasma en numerosas publicaciones nacionales e internacionales. Ha colaborado en dos proyectos de investigación (I+D) relacionados con el estudio de tejidos de la Antigüedad Tardía y Medievales.

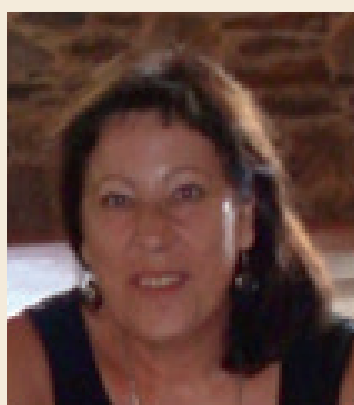

\section{Ángela Arteaga Rodríguez}

angela.arteaga@mecd.es

Área de Investigación y Formación. Instituto de Patrimonio Cultural de España (IPCE)

Oficial Industrial Rama Química y especialidad de Química de Laboratorio> (1972) por la Escuela de Maestría Industrial de Madrid.

Desde el año 1992 ha ejercido su profesión en la unidad de análisis de materiales del IPCE, realizando análisis de colorantes, proteínas, aglutinantes y morteros presentes en las obras de arte por diferentes técnicas como FTIR, TLC y HPLC.

Ha participado en diversas publicaciones congresos y otras reuniones profesionales, tanto nacionales como internacionales. 


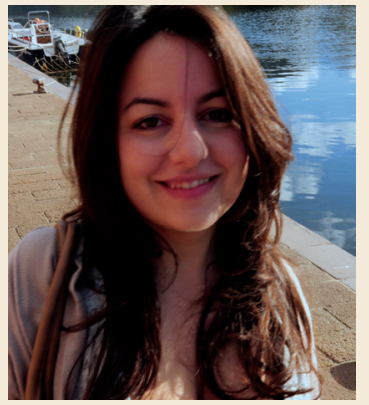

\section{Susanna marras}

susanna.marras@gmail.com

Área de Investigación y Formación. Instituto de Patrimonio Cultural de España (IPCE)

Licenciada en Química para la Conservación y la Restauración del Patrimonio Cultural por la Universidad Ca' Foscari de Venecia y Doctora en Química con tesis sobre "Caracterización avanzada de lacas y colorantes naturales en obras de arte pictórica". Desde el 2007 ha madurado experiencia en investigación académica en la Universidad de Venecia participando en proyectos de Patrimonio y de Medio Ambiente. Desde el 2013 colabora con el Instituto del Patrimonio Cultural de España (IPCE) ocupándose del análisis de colorantes en muestras de pintura y tejidos, y de la creación de una base de datos de colorantes naturales basada en estudio de patrones. Ha formado parte del equipo científico de los proyectos europeos NanoForArt y Nanorestart.

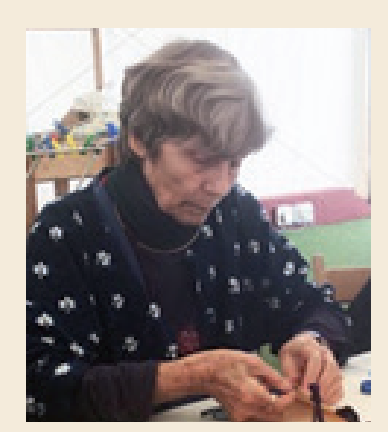

\section{Ana Roquero Caparrós}

anaroquero2@gmail.com

Investigadora en técnicas textiles, se especializa desde 1975 en el estudio de los tintes históricos y en la investigación etnobotánica y etnográfica sobre técnicas tradicionales de tintorería en América Latina, Norte de África y Cuenca Mediterránea.

Ha publicado regularmente libros y artículos y realizado exposiciones sobre este tema.

Colaboradora, entre otras instituciones, con el Instituto del Patrimonio Cultural de España (Madrid), Museo de América (Madrid), Real Jardín Botánico (Madrid) y Museo Británico (Londres). 